\title{
The Effect of Mark Enhancement Techniques on the Subsequent Detection of Saliva
}

Patricia McAllister, Eleanor Graham , Paul Deacon , Kevin J. Farrugia

This is the accepted manuscript (C) 2016, Elsevier

Licensed under the Creative Commons Attribution-NonCommercialNoDerivatives 4.0 International: http://creativecommons.org/licenses/bync-nd/4.0/

(c)) EY-NC-ND

Changes resulting from the publishing process, such as peer review, editing, corrections, structural formatting, and other quality control mechanisms may not be reflected in this document. Changes may have been made to this work since it was submitted for publication. A definitive version was subsequently published in Science \& Justice, DOI: 10.1016/j.scijus.2016.05.004 


\title{
The Effect of Mark Enhancement Techniques on the Subsequent Detection of Saliva
}

\author{
Patricia McAllister ${ }^{\mathrm{a}}$, Eleanor Graham ${ }^{\mathrm{b}}$, Paul Deacon ${ }^{\mathrm{c}}$, Kevin J. Farrugia ${ }^{\mathrm{a}, *}$ \\ ${ }^{a}$ School of Science, Engineering \& Technology, Division of Science, Abertay University, \\ Bell Street, Dundee, DD1 1HG, UK \\ ${ }^{\mathrm{b}}$ Northumbria University, Faculty of Health and Life Sciences, Department of Applied \\ Sciences, Ellison Building, Newcastle NE1 8ST, UK \\ ${ }^{c}$ c/o School of Science, Engineering \& Technology, Division of Science, Abertay University, \\ Bell Street, Dundee, DD1 1HG, UK
}

\section{* Corresponding Author:}

School of Science, Engineering \& Technology

Division of Science

Abertay University

Bell Street

Dundee DD1 1HG

United Kingdom

Tel: +44 (0) 1382308689

kevin.farrugia@abertay.ac.uk 


\begin{abstract}
There appears to be a limited but growing body of research on the sequential analysis/treatment of multiple types of evidence. The development of an integrated forensic approach is necessary to maximise evidence recovery and to ensure that a particular treatment is not detrimental to other types of evidence. This study aims to assess the effect of latent and blood mark enhancement techniques (e.g. fluorescence, ninhydrin, acid violet 17, black ironoxide powder suspension) on the subsequent detection of saliva.
\end{abstract}

Saliva detection was performed by means of a presumptive test (Phadebas ${ }^{\circledR}$ ) in addition to analysis by a rapid stain identification (RSID) kit test and confirmatory DNA testing. Additional variables included a saliva depletion series and a number of different substrates with varying porosities as well as different ageing periods. Examination and photography under white light and fluorescence was carried out prior to and after chemical enhancement

All enhancement techniques (except Bluestar ${ }^{\circledR}$ Forensic Magnum luminol) employed in this study resulted in an improved visualisation of the saliva stains, although the inherent fluorescence of saliva was sometimes blocked after chemical treatment. The use of protein stains was, in general, detrimental to the detection of saliva. Positive results were less pronounced after the use of black iron-oxide powder suspension, cyanoacrylate fuming followed by BY40 and ninhydrin when compared to the respective positive controls. The application of Bluestar ${ }^{\circledR}$ Forensic Magnum luminol and black magnetic powder proved to be the least detrimental, with no significant difference between the test results and the positive controls. The use of non-destructive fluorescence examination provided good visualisation; however, only the first few marks in the depletion were observed. Of the samples selected for DNA analysis only depletion 1 samples contained sufficient DNA quantity for further processing using standard methodology. The 28 day delay between sample deposition and collection resulted in a 5-fold reduction in the amount of useable DNA. When sufficient DNA quantities were recovered, enhancement techniques did not have a detrimental effect on the ability to generate DNA profiles.

This study aims to contribute to a strategy for maximising evidence recovery and efficiency for the detection of latent marks and saliva. The results demonstrate that most of the enhancement techniques employed in this study were not detrimental to the subsequent detection of saliva by means of presumptive, confirmative and DNA tests. 


\section{Keywords}

Integrated forensic approach,

Phadebas ${ }^{\circledR}$,

RSID saliva test,

Fluorescence,

Finger/footwear mark enhancement,

DNA 


\section{Introduction}

Multiple types of evidence may be collected from the same substrate; however, there are limited recommendations and guidelines for such methodology. Frequently encountered types of evidence include latent marks [1] and body fluids [2]. If these two types of evidence are present, then the application of two different tests is required. This leads to the important question - which test should be applied first and how does this test affect the other test and the evidence? Biological tests and DNA analysis are important; however, if the stain is not visible, speculative swabbing must be done which may be detrimental to latent finger/footwear marks [1]. The use of certain enhancement techniques can provide enhancement of latent finger/footwear marks as well as other body fluid stains. This study aims to assess the effect of such enhancement techniques on the visualisation and subsequent detection of saliva by means of presumptive and confirmatory tests.

\section{Saliva}

Saliva is composed of mainly water (>99\%) in the presence of buccal epithelial cells, enzymes, salts, mucin and $\alpha$-amylase that is responsible for the breakdown of starch [3]. In the UK, saliva has been reported as the most common source of DNA in volume crime [4]. Although the presence of $\alpha$-amylase is indicative of human saliva, this is not proportional to the amount of DNA in a stain due to other variables such as age of stain and different donors [5]. $\alpha$-amylase may be present in other mammal's saliva [6] as well as other body fluids such as breast milk, seminal fluid and perspiration; however, the concentration is considerably lower than that found in saliva [7,8]. Whitehead and Kipps [9] reported the $\alpha$-amylase activity of saliva at 263,000 - 376,000 IU/L and urine at $263-940 \mathrm{IU} / \mathrm{L}$ with blood, semen, nasal secretion and sweat having considerably smaller values. The use of IU/L (International Units/Litre) is an arbitrary measurement which is often used with enzyme concentrations.

Dried saliva stains will generally fluoresce under an excitation wavelength range of 300$480 \mathrm{~nm}[10,11]$. It has however been reported that as many as $40 \%$ of saliva stains on clothing can be undetected by alternate light sources [12]. Fluorescence examination using this broad range is useful for speculative searching but does not necessarily identify which body fluid is present. Furthermore, long exposure times to such fluorescence may be detrimental to subsequent DNA analysis. In addition to colour tests for the detection of saliva, recent advances using analytical techniques such as Raman spectroscopy [2,13-15], fluorescent spectroscopy [16] and in situ analysis with specific antibody-nanoparticle conjugates have been discussed [17]. 


\section{Presumptive tests for saliva}

$\alpha$-amylase is considered as a suitable indicator to the presence of saliva due to its higher concentrations, although other constituents of saliva such as thiocyanate, nitrite and alkaline phosphatase can be considered [18]. The use of amylase for saliva detection was discussed as early as in 1881 using the starch-iodine test; however since the 1970s, a commercially manufactured product called Phadebas ${ }^{\circledR}$ has been used $[19,20]$. The Phadebas ${ }^{\circledR}$ forensic tube test is a presumptive test for the detection of saliva which reacts with the $\alpha$-amylase present. The Phadebas ${ }^{\circledR}$ test involves combining an extract of a saliva stain with a Phadebas ${ }^{\circledR}$ tablet containing biodegradable starch microspheres covalently bound to a blue dye. This covalent bond inhibits water solubility; however, the bond is broken in the presence of $\alpha$-amylase and a blue dye is released proportional to the $\alpha$-amylase activity, as long as all other variables are kept constant (i.e. extract volume, extraction time, incubation time). The concentration of the dye can be calculated with the use of a spectrophotometer and used as a semi-quantitative measurement for the amount of amylase within the sample. Although amylase activity in saliva is considerably higher compared to other body fluids, this activity decreases rapidly with ageing and may lead to misinterpretation of the results such as the example discussed by Gutowski and Henthorn [21] where "one-month-old saliva stains and fresh stains from other amylase-containing sources such as urine could be similar".

The Phadebas ${ }^{\circledR}$ forensic tube test requires adherence to procedures given by the manufacturer such as incubation at $37^{\circ} \mathrm{C}$ for a set amount of time. More recently, a Phadebas ${ }^{\circledR}$ forensic press test was developed to speed up the process where a pre-treated filter paper is pressed against a suspected saliva stain that gives a blue colouration in the presence of $\alpha$-amylase; however, the manufacturer reports that it is less sensitive than the tube test. A comparison between the Phadebas ${ }^{\circledR}$ forensic press test and alternate light sources from different manufacturers for the detection of saliva showed that, on certain substrates, the press test resulted in a higher detection rate. The sensitivity increased from 1:100 to 1:200 dilution when incubated at $37^{\circ} \mathrm{C}$ rather than at room temperature, albeit with limited reproducibility [22]. DNA analysis after the press test is still possible; however, there is no correlation between amylase activity and amount of DNA in fresh saliva [5]. In another study [23], both the tube and the press test are reported to have similar sensitivity. 
The SALIgAE® saliva test is another colorimetric test which in the presence of saliva gives a yellow colour; however, similar to the Phadebas ${ }^{\circledR}$ test, other body fluids might give a similar colouration as well $[24,25]$. In a particular study [24], the SALIgAE® saliva test was shown to be inferior to the Phadebas ${ }^{\circledR}$ test in terms of specificity and sensitivity to the saliva.

\section{RSID TM-Saliva test}

Rapid Stain Identification (RSID ${ }^{\mathrm{TM}}$ ) kits developed by Independent Forensics (Lombard, IL, USA) are lateral flow immunochromatographic strip tests designed for identifying body fluids such as blood, semen, urine and saliva. A buffer solution is used to extract the body fluid which is then introduced to the strip where a positive or negative reaction is recorded by the development of a red line. Since this line may be weak and subjective to interpretation, a $\mathrm{RSID}^{\mathrm{TM}}$ reader system analyses the pixel density of the developed test and control lines [26]. RSID $^{\mathrm{TM}}$-Saliva utilises two anti-salivary $\alpha$-amylase monoclonal antibodies to detect the presence of salivary amylase, rather than the activity of the enzyme and the manufacturer reports the test as accurate, reproducible, easy to use, and highly specific for human saliva [27]. Once a stain is detected, the remaining extract can then be submitted for DNA analysis since the test is not detrimental to such analysis.

Although this test is highly specific to human saliva, one can argue whether it is a confirmatory test for human salivary $\alpha$-amylase. The saliva test denoted a negative reaction for many different types of animal saliva; however, it denoted a positive reaction for gorilla saliva [27]. A number of studies [6,28] reported the $\operatorname{RSID}^{\mathrm{TM}}$-Saliva kit as more sensitive and specific in comparison to the SALIgAE® and Phadebas ${ }^{\circledR}$ tests. Nonetheless, the RSID ${ }^{\mathrm{TM}}$ kit gave a positive reaction with rat saliva and human pancreatic $\alpha$-amylase [6]. There might also be a reaction with other body fluids such as breast milk, urine and semen but this appears to be limited and was also observed with the SALIgAE® and Phadebas ${ }^{\circledR}$ tests $[6,28]$. The RSID kit was also found be the most suitable technique for the detection of saliva in expectorated blood when compared to SALIgAE®, Phadebas $®$ and starch gel diffusion [29]. Furthermore, the $\mathrm{RSID}^{\mathrm{TM}}$-Saliva kit was determined to be resistant to factors such as ageing (up to 40 days old saliva stains) and environmental conditions (sunlight near window) [30]; however its efficiency varied on different substrates [31]. Potential false positives for the presence of saliva using the $\operatorname{RSID}^{\mathrm{TM}}$ kit have been reported with citrus fruits [32] but not with undiluted detergents; however, some detergents did give a false positive with Phadebas ${ }^{\circledR}[33]$. 


\section{Integrated forensic approach}

It is clear that an integrated forensic approach is necessary as an overall strategy to maximise the evidence recovery and efficiency. This has long been recognised in terms of fingermark enhancement and in which sequence different techniques are applied [1]. It is also recognised that one should start with photography followed by non-destructive techniques and then by destructive or chemical techniques. Numerous studies [34-56] have investigated the effect of fingermark enhancement techniques on subsequent DNA analysis. Such studies have shown that certain techniques (e.g. cyanoacrylate fuming, vacuum metal deposition and luminol) are not detrimental to DNA analysis whereas others are (e.g. physical developer and silver nitrate). The amount of cellular material for DNA may be less but detectable after subjected to the enhancement techniques; however, this depended on a number of other variables such as size of stain, donor, substrate and age factors.

Other studies [57-64] examined the effects of certain enhancement techniques on subsequent presumptive tests or whether certain processes, for example decontamination CBRNE, affected fingermark recovery. Bitner et al. [65] reported that the use of ninhydrin (petroleumether-based formulation) had little or no effect on the detection of the $\alpha$-amylase protein present in saliva on envelopes using Phadebas ${ }^{\circledR}$, SALIgAE® and RSID $^{\mathrm{TM}}$-Saliva kit. The effect of latent mark enhancement techniques on the presumptive and confirmatory test for semen/spermatozoa was also investigated [66]. All techniques investigated resulted in improved visualisation of the stain and only powder suspension was detrimental to both the presumptive and confirmatory test for semen/spermatozoa. The protein stains acid violet 17 and acid yellow 7 resulted in loss of the presumptive test because acid phosphatase is water soluble; however, the observation of sperm heads for confirmatory test was still possible [66]. The study presented here aims to further the research for an integrated forensic approach by investigating the effects that mark enhancement techniques may have on the subsequent detection of saliva on the same substrate. Nine fingermark and blood enhancement techniques were included in this study: general fluorescence, acid violet 17 (AV17), acid yellow 7 (AY7), ninhydrin, DFO, black magnetic powder, black iron-oxide powder suspension, Bluestar ${ }^{\circledR}$ Forensic Magnum luminol and cyanoacrylate fuming with subsequent basic yellow 40 (BY40) treatment. The sequence of mark enhancement followed by tests for the detection of $\alpha$-amylase was selected since the opposite sequence may damage the fine detail of latent marks. The effect of the enhancement techniques on the subsequent detection of saliva was investigated by visual and fluorescent examination followed by $\alpha$-amylase

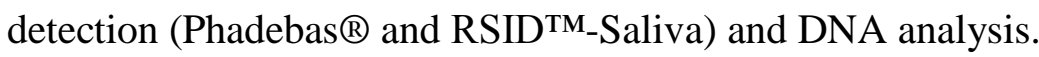




\section{Methodologies and Materials}

\section{Substrate preparation}

White ceramic tiles, grey laminate flooring, brown envelopes and newspaper were used as substrates in this study. White tiles were obtained as new locally and measured approximately $15 \mathrm{~cm} \times 15 \mathrm{~cm}$ and the grey laminate, which had been previously used as kitchen flooring, was cut to a smaller size of $13 \mathrm{~cm} \times 15 \mathrm{~cm}$ using an electric saw. The envelopes were purchased in bulk in unopened packages and the newspaper purchased in bulk on the $15^{\text {th }}$ January 2015 . The porous substrates did not require washing before use but the non-porous substrates were washed thoroughly using detergent and a sponge, before being rinsed with tap water and dried using blue paper towels. All substrates were checked by fluorescence, including after washing, to ensure they were clean. Grids were marked out for the saliva deposition with a black china marker.

\section{Sample deposition}

Saliva was obtained from two donors, a male and a female, both 23 years old. Fresh saliva samples were obtained from each donor on the same day they would be required for deposition. The saliva samples were obtained in the morning, between 08:00 and 12:00 and required the donor to hold their tongue up for one minute before using a sterile plastic pipette to remove the saliva which had collected underneath the tongue [67]. In practise, this method took several minutes to achieve a sufficient volume of saliva. Sterile glass screw top vials were used to store the saliva and used to create a depletion series as soon as possible thereafter. The saliva samples were obtained at least half an hour after brushing teeth and at least one hour after eating or drinking anything. This was to ensure that the samples were collected under near constant conditions, to minimise the variation in amylase concentrations.

Three identical stamps (approximately $2 \mathrm{~cm}^{2}$ ) with minimal pattern were purchased for use with the female sample, male sample and controls. Sterile petri dishes were used to hold each saliva sample, a $1 \%$ Virkon disinfectant solution and distilled water. The stamps were washed before use by dipping into the Virkon solution followed by dipping into distilled water and drying using blue paper towel. The stamps were then dipped into the saliva sample three times before making a depletion series on each substrate. A depletion series of 50 and 30 saliva stamps was used for the non-porous and porous substrates respectively. An attempt 
was made to keep the deposition pressure as constant as possible. The stamps were also washed between each depletion series.

\section{Control tests}

Positive and negative controls were prepared for each donor, ageing period, substrate and enhancement technique. The positive controls were prepared and left to age in the same way as the samples which were to be processed with enhancement techniques; however, these controls were not processed with any enhancement techniques. The positive controls were prepared to ensure that the saliva samples which were being used would give a positive result before they were altered in any way with the enhancement techniques.

For the negative controls, a clean stamp, which had not been in contact with any saliva, was used to deposit distilled water on to separate pieces of substrate. The stamp was dipped into distilled water three times and a depletion series created for all variables. These negative controls were aged in the same way as the substrates containing saliva, before treatment with the enhancement techniques and testing for the presence of saliva.

\section{Ageing of samples}

The saliva stains on the substrates were left to age for $1,7,14$ and 28 days after deposition. The substrates were stored on shelving units within the laboratory, which was dry and had no direct sunlight, although the temperature and humidity of this environment were not controlled.

\section{Examination and photography}

Before and after enhancement, each depletion series in saliva was examined and photographed using a Nikon D5100 digital SLR camera with a 55mm lens under white light and fluorescence using a Quaser 2000/30. Best contrast for the fluorescence examination of saliva was observed using a violet/blue excitation source (band pass filter 400-469 $\mathrm{nm}$ at $1 \%$ cut-on and cut-off points respectively) and viewed with a yellow long pass $476 \mathrm{~nm}$ filter (1\% cut-on point). UV examination was carried out using a 50W Labino SuperXenon Lumi Kit (peak excitation at $325 \mathrm{~nm}$ ) and viewed with a clear UV filter. The number of saliva marks visualised at each stage of enhancement was recorded and compared to before the application of enhancement techniques. The use of a blue Crime-Lite ${ }^{\circledR} 82 \mathrm{~S}[10 \%$ band width $420-470 \mathrm{~nm}$ with a $445 \mathrm{~nm}$ peak and viewed with a yellow long pass $476 \mathrm{~nm}$ filter (1\% cut-on point)] was also investigated. 
All chemical formulations taken from the Fingermark Visualisation Manual [1]. All solvents used in the following formulations were of analytical grade.

\section{$\underline{\text { Black magnetic powder }}$}

A magnetic brush was used to apply black magnetic powder (CSI Equipment Ltd., UK)

\section{Iron-oxide black powder suspension}

Iron (II/III) oxide (20g, Fisher Scientific, I/1100/53) was weighed out and transferred into a $100 \mathrm{~mL}$ glass beaker. Stock detergent solution $(20 \mathrm{~mL})$ prepared using Triton X100 (250 mL, Acros), ethylene glycol (350 mL, Acros) and distilled water (400 mL) was then added. This mixture was stirred until no lumps remained. The suspension was then applied using an animal hair brush and left for 10-15 seconds before careful rinsing under tap water. Substrates were allowed to dry overnight before further examination.

\section{Ninhydrin}

A concentrated ninhydrin solution was prepared by dissolving ninhydrin (25 g, Sigma) in ethanol (225 mL, Sigma), ethyl acetate (10 mL, Sigma) and acetic acid (25 mL, Sigma). The solution was stirred until a clear yellow solution was produced. The working solution was then prepared by the addition of HFE7100 (1 L, 3M Novec) to $52 \mathrm{~mL}$ ninhydrin working solution. Each sample was drawn through the ninhydrin solution and the excess liquid allowed to drain back in the tray. After drying, the samples were treated in a Gallenkamp humidity oven at $80^{\circ} \mathrm{C}$ and a nominal $65 \%$ relative humidity for 4 minutes. The subsequent enhancement was observed immediately and monitored over the next 7 days.

\section{$\underline{\mathrm{DFO}}$}

DFO (0.25 g, Sirchie) was dissolved in methanol (30 mL, Sigma) using a magnetic stirrer to produce a slurry. Acetic acid (20 mL, Sigma) was added and stirred until a clear, yellow solution was produced followed by the addition of HFE71DE (275 mL, 3M Novec) and HFE7100 (725 mL, 3M Novec) with continued stirring. Each sample was drawn through the DFO solution and the excess liquid allowed to drain back in the tray. After drying, the samples were treated in an oven at $100{ }^{\circ} \mathrm{C}$ for 20 minutes. Fluorescence examination was carried out using a green excitation source (band pass filter 473-548 $\mathrm{nm}$ at $1 \%$ cut-on and cutoff points respectively) and viewed with a band-pass $549 \mathrm{~nm}$ filter (1\% cut-on point). 


\section{Cyanoacrylate fuming/BY40}

$2 \mathrm{~g}$ of cyanoacrylate (CSI equipment Ltd, UK) was placed into a new foil dish and positioned on a clean support ring on a heat source of about $100^{\circ} \mathrm{C}$ in the fuming chamber (Air Science CA305). The cabinet was then set to run at $80 \%$ humidity for 45 minutes to ensure evaporation of all cyanoacrylate. After fuming, the fluorescence of saliva was checked to observe the effects of cyanoacrylate on the fluorescence. The next day, the fumed articles were immersed in a BY40 solution for 15 seconds followed by thorough rinsing under running tap water and left to dry at room temperature before BY40 fluorescence examination. Basic yellow 40 (2 g, Sirchie) dye was prepared by dissolving in ethanol (1 L, Fisher). Fluorescence was observed by exciting with a violet/blue excitation source (band pass filter $350-469 \mathrm{~nm}$ at $1 \%$ cut-on and cut-off points, respectively) and viewed with a yellow long pass $476 \mathrm{~nm}$ filter (1\% cut-on point).

\section{$\underline{\text { Acid violet } 17 \text { (AV17) and acid yellow } 7 \text { (AY7) }}$}

AV17 and AY7 treatment is carried out via a three stage process involving fixation, staining and destaining. The fixative solution was prepared by dissolving 5-sulfosalicylic acid dehydrate $(23 \mathrm{~g}$, Acros) in distilled water $(1 \mathrm{~L})$ and stirring for at least 30 minutes. Fixation was carried out first for a minimum of 5 minutes before transferring to a staining solution for a minimum of 10 minutes. The staining solution was prepared by dissolving the appropriate protein stain (1 g of AV17 or AY7, BVDA) in acetic acid (50 mL, Fisher), ethanol (250 mL, Fisher) and distilled water $(700 \mathrm{~mL})$. The de-staining procedure consisted of thorough rinsing in a solution of acetic acid (50 mL, Fisher), ethanol (250 mL, Fisher) and distilled water (700 $\mathrm{mL}$ ). After drying, AY7 fluorescence was observed with a blue excitation source (band pass filter $385-509 \mathrm{~nm}$ at $1 \%$ cut-on and cut-off points, respectively) and viewed with a long pass yellow/orange $510 \mathrm{~nm}$ filter (1\% cut-on point).

\section{$\underline{\text { Bluestar} ® ~ F o r e n s i c ~ M a g n u m ~ L u m i n o l ~}$}

Bluestar Forensic Magnum luminol was prepared by mixing the three tablets and $125 \mathrm{~mL}$ of liquid supplied with delivery through an Ecospray® fine mist sprayer (nozzle diameter: 0.70 $\mathrm{mm}$, flow rate: $0.45 \mathrm{~mL} / \mathrm{s}$ ) at a distance of approximately $15-20 \mathrm{~cm}$. The prepared solution was used within $24 \mathrm{~h}$ of mixing and substrates were then left to dry for $24 \mathrm{~h}$ before further examination. 


\section{Extraction of saliva from surface of substrate}

Depletions 1, 18 and 30 were included for a porous substrate example (envelopes) and depletions 1, 18 and 39 were included for a non-porous substrate example (tile). The saliva stains were extracted from both the tiles and envelopes by swabbing the surface of the substrates using a method adapted from Sweet et al. [68]. The swab was submerged in sterile distilled water in order to completely wet the tip, which was then rolled over the surface of the substrate. This was carried out using moderate pressure while rotating the swab, in order to increase the contact between the swab end and the surface of the substrate. The swab end was cut off and placed into a $2 \mathrm{~mL}$ plastic tube. Two swabs were taken from each sample being tested: one swab for the Phadebas ${ }^{\circledR}$ test (upper half) and one swab for the RSID ${ }^{\text {TM }}$ test (lower half). When no residue was observed (visual and/or fluorescent) on the substrate, the swabs were taken from the upper and lower halves of the grid square in question. The saliva donors did not perform any of the analyses.

\section{Phadebas® testing}

After the Phadebas ${ }^{\circledR}$ swab was taken and placed into a $2 \mathrm{~mL}$ plastic tube, the tube was filled up to $1 \mathrm{~mL}$ with sterile distilled water and agitated using a vortex mixer. After several minutes, the supernatant was transferred to another tube, before adding in half a Phadebas ${ }^{\circledR}$ tablet and filling to the $1 \mathrm{~mL}$ mark with sterile distilled water. The tubes were agitated then incubated for half an hour using a water bath at $37{ }^{\circ} \mathrm{C}$. After the incubation, the tubes were again agitated and centrifuged at $10000 \mathrm{~g}$ for 5 minutes. The colour of the supernatant was recorded in order to determine whether or not the swab had tested positive for amylase. The colour was observed immediately and graded negative if the supernatant was clear or positive if it was blue. The positive gradings ranged from +1 to +4 depending on the intensity of the blue colour (intensity is dependent on amylase concentration). The grading was performed by one person for consistency.

\section{$\underline{\text { RSID }^{\text {TM}}-\text { Saliva testing }}$}

$300 \mu \mathrm{L}$ of RSID ${ }^{\mathrm{TM}}$ Universal Buffer was added to the swab in a $1.5 \mathrm{~mL}$ plastic tube and allowed to extract for 2 hours. $20 \mu \mathrm{L}$ of this extract was then diluted to $100 \mu \mathrm{L}$ with $\mathrm{RSID}^{\mathrm{TM}}$ Universal Buffer. This $100 \mu \mathrm{L}$ sample was then added to the sample window of a RSID ${ }^{\text {TM }}$ Saliva kit and after exactly 10 minutes, as instructed by the manufacturer, the results were recorded and photographed. The scoring results were negative, positive or failed test as indicated in figure 1 [69]. 


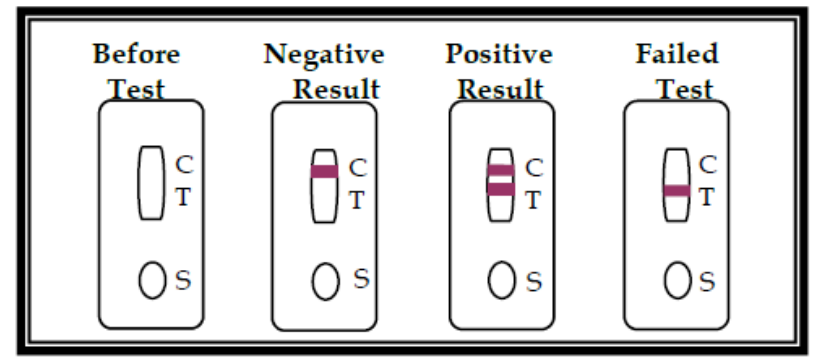

Figure 1 - Evaluation of a RSID ${ }^{\text {TM}}$-Saliva kit after 10 minutes showing examples of a negative, positive and failed test (C - Control; $\mathbf{T}$ - Test; $\mathbf{S}$ - Sample Window) [69]

\section{$\underline{\text { DNA Analysis }}$}

DNA was extracted from the remaining volume of RSID extraction buffer from day 1 and 28 samples. Deposits 1, 18 and 30 were processed from the porous substrate and 1, 18 and 39 from the non-porous substrate. A modified QIAamp Blood Mini kit (QIAGEN, Venlo, Limburg, Netherlands) protocol that included the use of a QIAshredder column (QIAGEN, Venlo, Limburg, Netherlands) to remove residual solid particles associated with the enhancement methods was employed. The volume of liquid was made up to $400 \mu 1$ using sterile PBS before the addition of $400 \mu \mathrm{l}$ Buffer AL and $20 \mu$ l Protease solution. Following incubation at $56{ }^{\circ} \mathrm{C}$ for 10 minutes, with occasional mixing, the swab head was transferred to a $0.5 \mathrm{~mL}$ plastic tube with hole in the bottom which was placed inside a $2.0 \mathrm{~mL}$ tube. This apparatus was centrifuged at $14800 \mathrm{rpm}$ for 1 minute to recover liquid and DNA containing material from the swab head. Total liquid for each sample was then transferred to a QIAshredder column and was centrifuged at $14800 \mathrm{rpm}$ for 2 minutes. Liquid was recovered to the original $1.5 \mathrm{~mL}$ plastic tube, taking care to avoid any solid particles that had passed through the column and $400 \mu \mathrm{l}$ absolute ethanol was added and mixed. Liquid was added to a QIAamp Spin Column in two batches of approximately $610 \mu 1$, and was centrifuged for 1 minute at $8000 \mathrm{rpm}$, with the flow-through being discarded after the first application. Manufacturers' recommendations were followed for the rest of the protocol, with DNA being recovered in $60 \mu \mathrm{l}$ Buffer $\mathrm{AE}$ after 5 minutes incubation at room temperature. Samples were extracted in batches of 9 and with the inclusion of an extraction negative control, consisting of an unopened DNA-free swab with each batch. All DNA extracts were quantified using the Quantifiler Duo real-time PCR quantification kit (Thermo Fisher Scientific, Oyster Point, CA, USA) following manufacturer's instructions. Samples with quantification results greater than $0.01 \mathrm{ng} / \mu \mathrm{l}$ were amplified using the SGM plus amplification kit (Thermo Fisher Scientific, Oyster Point, CA, USA) in a total reaction volume of $25 \mu \mathrm{l}$ using 28 cycles. $10 \mu \mathrm{l}$ undiluted DNA was added from each extract and positive/negative controls were used in each amplification batch. 


\section{Results and Discussion}

\section{Controls}

Positive controls of saliva fluoresced under different wavelengths; however, best results were observed with blue light (yellow filter). Expected results for positive controls were observed

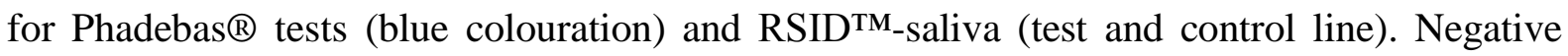
controls did not fluoresce and no colouration was observed with Phadebas ${ }^{\circledR}$ test.

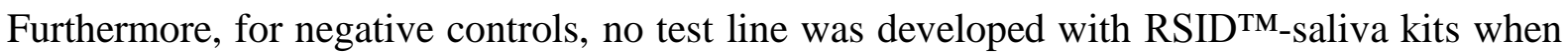
observed within 10 minutes as instructed by the manufacturer.

\section{Visual and fluorescent examination}

\section{$\underline{\text { Before enhancement }}$}

There were no major differences, visual or fluorescent between samples from different donors and which had undergone different ageing periods. Some observed variation may be attributed to the fact that amylase concentrations in saliva can vary significantly from day to day. The difference may also be attributed to uneven stamping and the porosity of the substrates. Throughout each ageing period, the envelopes, newspaper and laminate did not produce any visible marks under white light and only faint residues of the first few depletions were visible on tile where the use of oblique lighting slightly improved visualisation. The fluorescence of saliva was examined using various excitation and viewing filters; however, the best contrast was observed by using a violet/blue excitation source (band pass filter 400$469 \mathrm{~nm}$ at $1 \%$ cut-on and cut-off points respectively) and viewed with a yellow long pass 476 $\mathrm{nm}$ filter ( $1 \%$ cut-on point). Under fluorescence, faint marks could be observed up to the $25^{\text {th }}$ depletion on tiles (figure 2); however, there was minimal fluorescence on other substrates. Fluorescence examination on tiles provided the best improvement when compared to white light and in general, there was no significant difference in the number of marks observed across the ageing periods used in this study. The use of a blue Crime-lite ${ }^{\circledR} 82 \mathrm{~S}$ allowed the visualisation of marks further down the depletion series on tiles as a result of stronger wattage; however, other substrates did not yield any improvement over the Quaser 2000/30. 


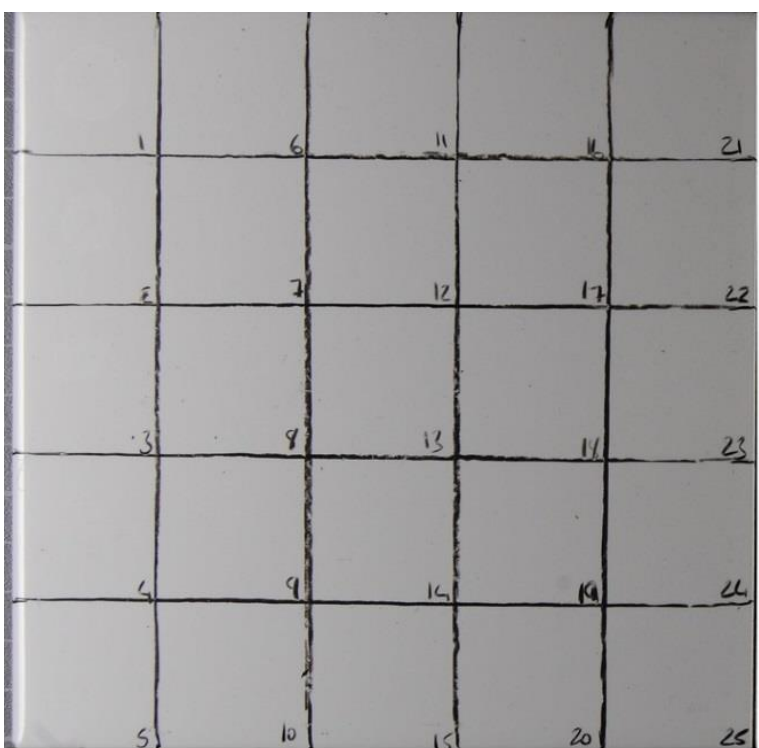

(a)

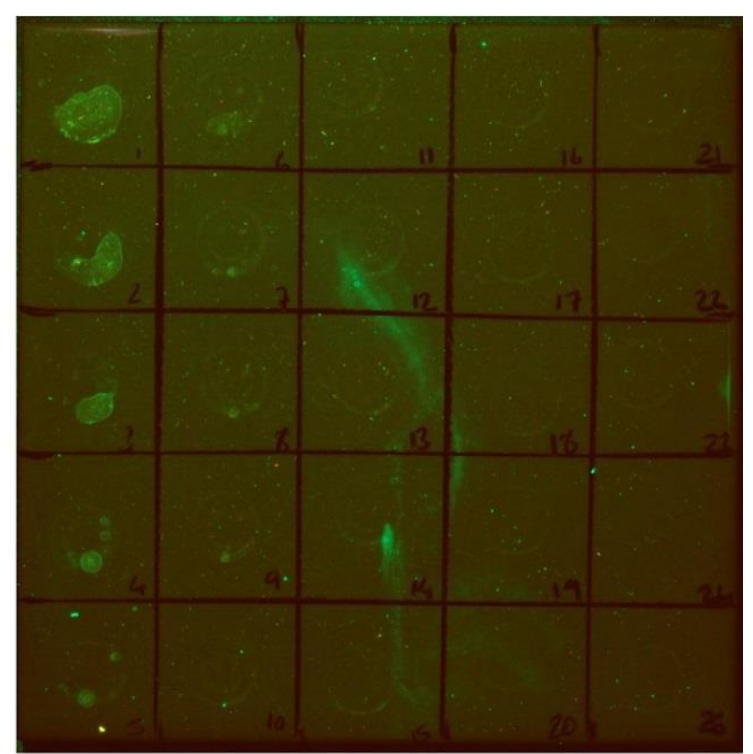

(b)

Figure 2 - Male saliva deposits 1-25 in the depletion series on white ceramic tile aged 28 days before enhancement: (a) under white light and (b) violet-blue light (yellow filter).

\section{After enhancement}

Figure 3 summarises the number of marks detected for each technique and substrate for saliva stains aged for 28 days from a male donor. A depletion series of 50 marks was employed for non-porous substrates (white and violet/blue light (yellow filter), AV17, AY7, black magnetic powder, CA/BY40, Bluestar Forensic Magnum luminol, black iron-oxide powder suspension) and 30 marks for porous substrates (white and violet/blue light (yellow filter), AV17, black magnetic powder, DFO, ninhydrin, Bluestar Forensic Magnum luminol). Similar results were observed for other ageing periods and for the two donors. Figures 4 and 5 demonstrate the enhancement observed after the use of various enhancement techniques under white light and fluorescence. 


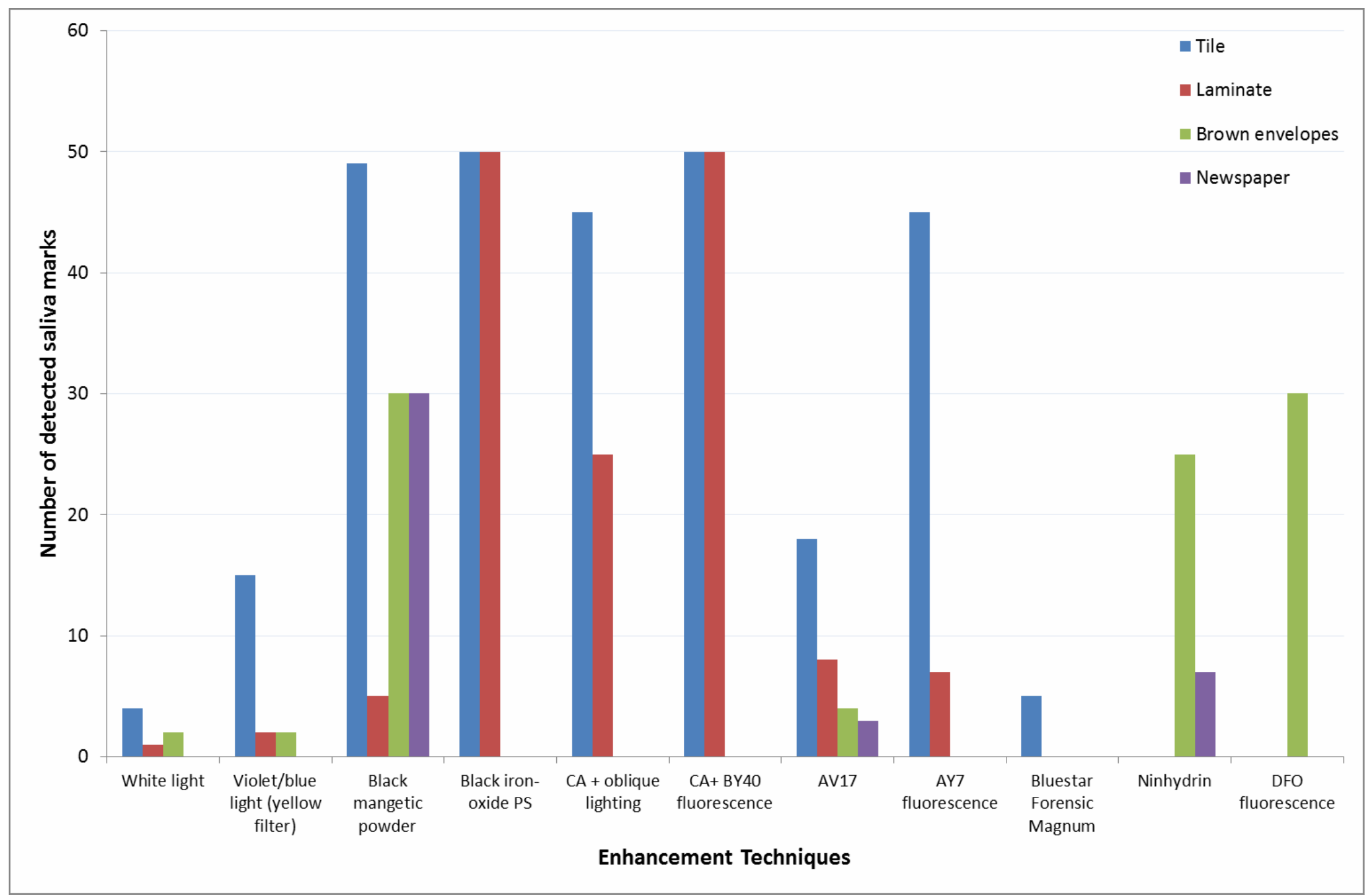

Figure 3 - Number of saliva marks observed before enhancement (white light) and after enhancement at 28 days ageing (male donor). 


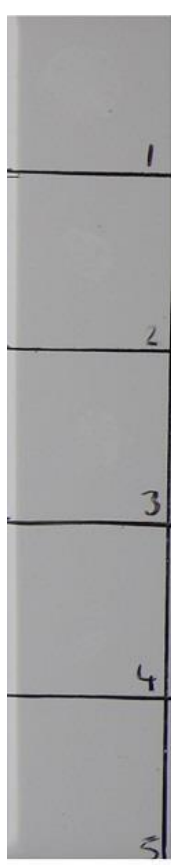

(a)

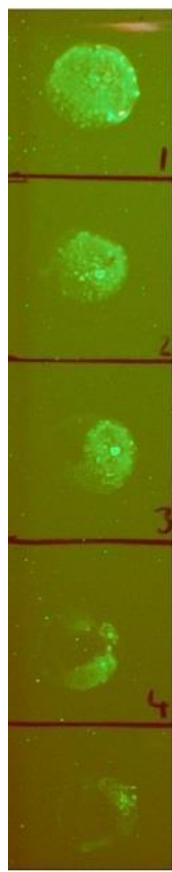

(b)

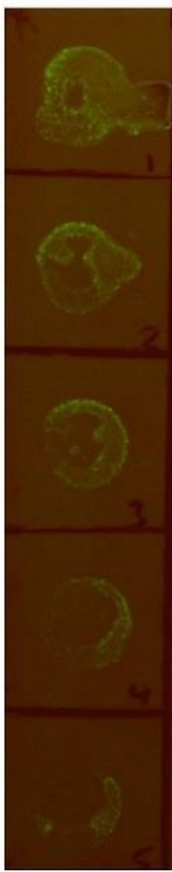

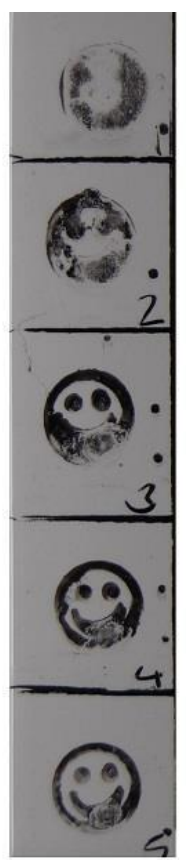

(c)

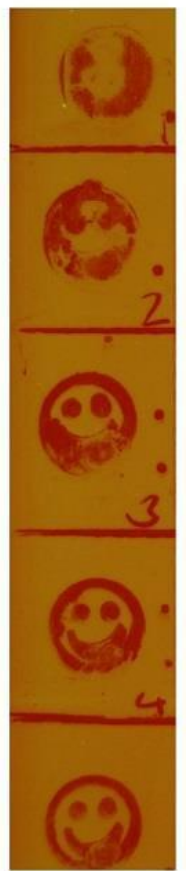

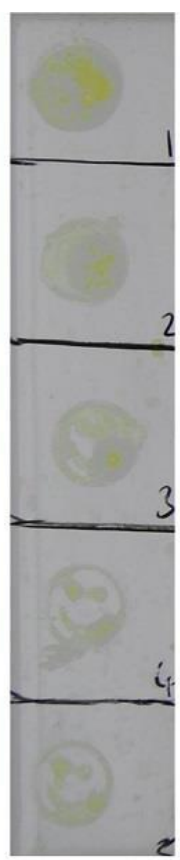

(d)

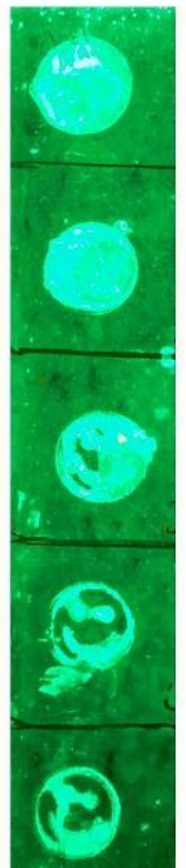

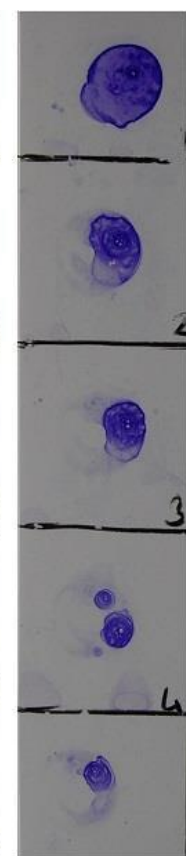

(e)

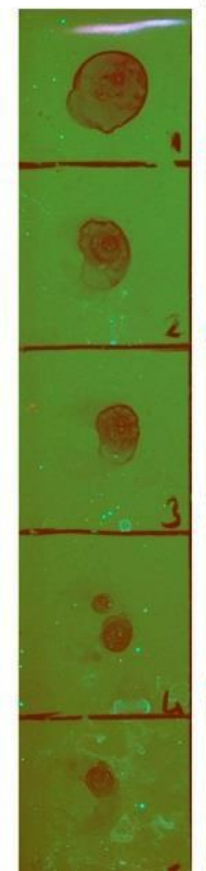

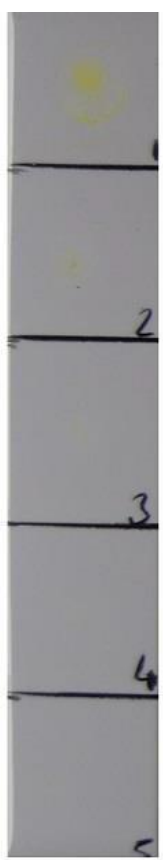

(f)

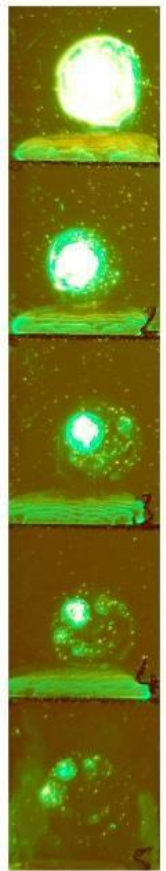

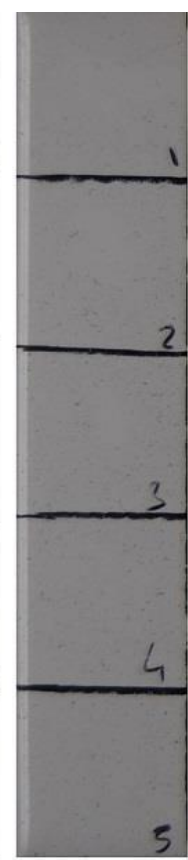

(g)

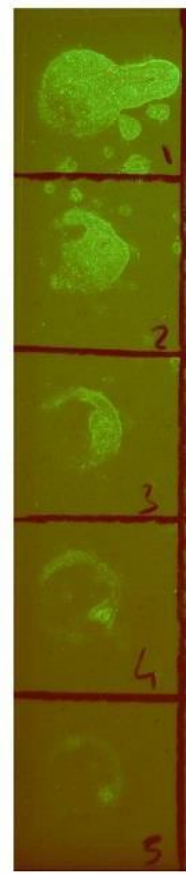

Figure 4 - Male saliva deposits 1-5 in the depletion series on white ceramic tile aged 28 days and viewed under white light (top) and blue light with yellow filter (bottom) post enhancement: (a) control before enhancement; (b) black magnetic powder; (c) black iron-oxide powder suspension; (d) cyanoacrylate/BY40; (e) AV17; (f) AY7; (g) Bluestar® forensic magnum. 


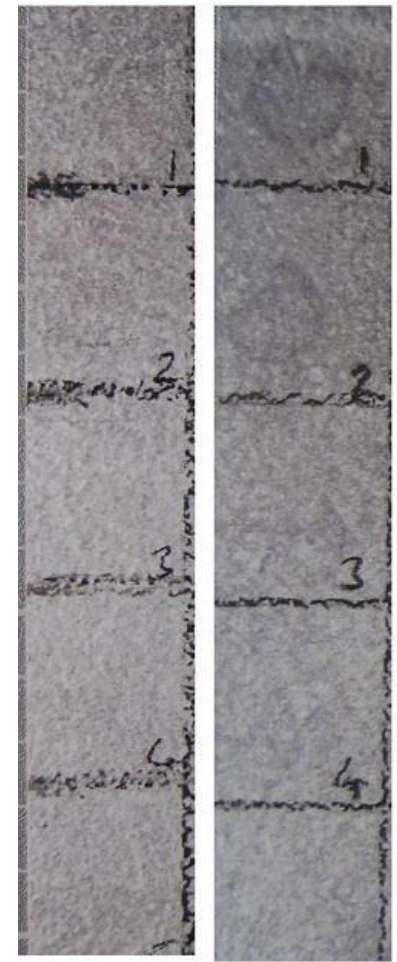

(a)

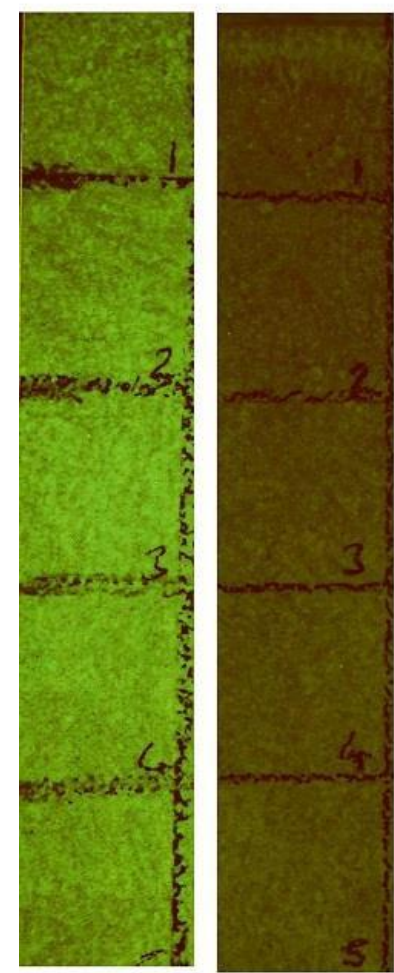

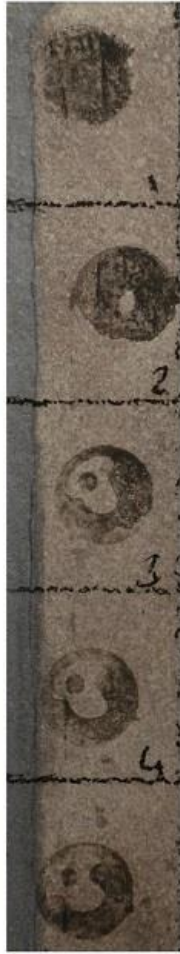

(c)

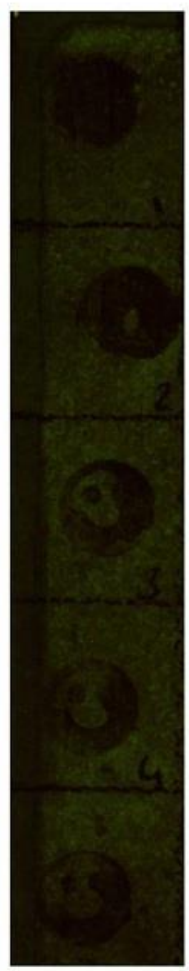

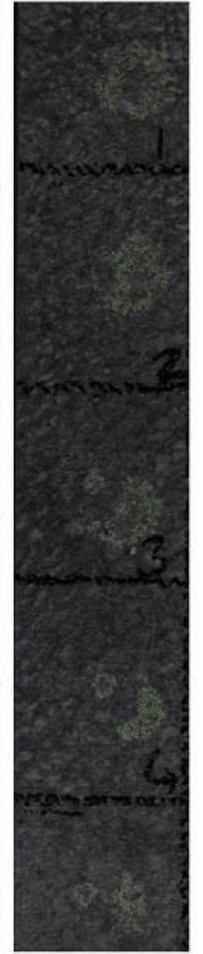

(d)

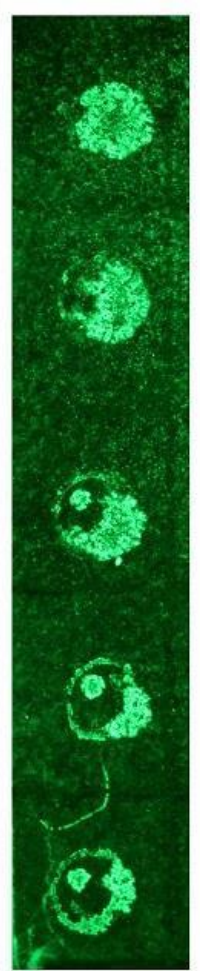

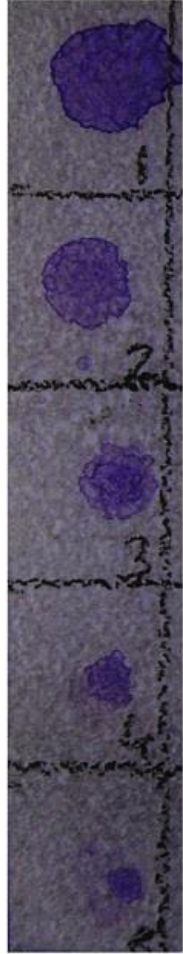

(e)

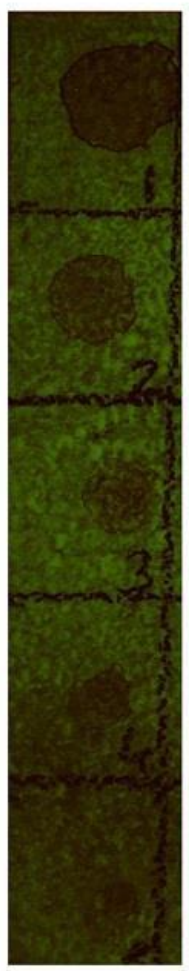

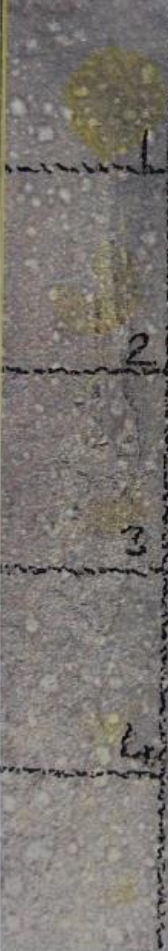

(f)

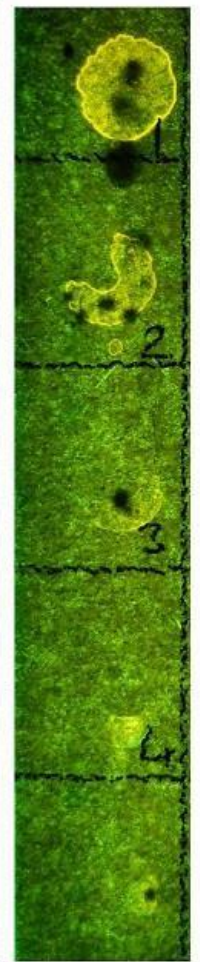

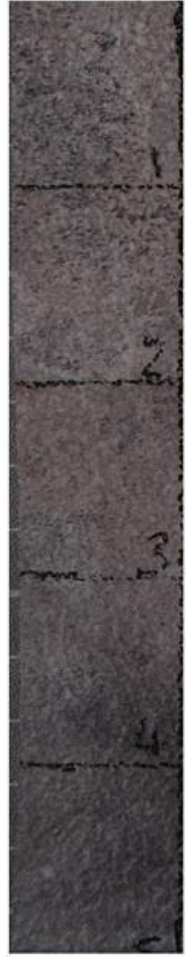

(g)

Figure 5 - Male saliva deposits 1-5 in the depletion series on grey laminate flooring aged 28 days and viewed under white light (top) and blue light with yellow filter (bottom) post enhancement:

(a) control before enhancement; (b) black magnetic powder; (c) black iron-oxide powder suspension; (d) cyanoacrylate/BY40; (e) AV17; (f) AY7; (g) Bluestar® forensic magnum 
In general, the use of black magnetic powder enhanced saliva residues on all four substrates examined in this study. The number of marks visualised on tiles was greatly increased regardless of ageing period and up to the $50^{\text {th }}$ depletion; however, the quality and level of enhancement was minimal on laminate flooring. For porous substrates, a negative mark was observed where the powder adhered to the background rather than the saliva residues (figure 6c). Occasionally, the inherent fluorescence of saliva was inhibited after the use of black magnetic powder with no obvious correlation to gender, ageing period or substrate. Black iron-oxide powder suspension adhered to all saliva residues present on non-porous substrates, greatly improved the visualisation where detection up to the $50^{\text {th }}$ depletion was observed (figure 7). The use of powder suspension in this study also resulted in the inhibition of the inherent fluorescence of saliva.

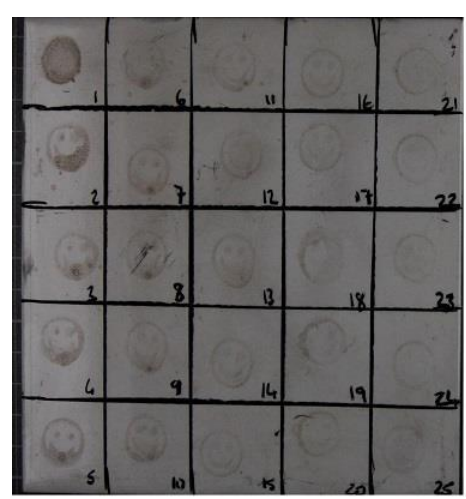

(a)

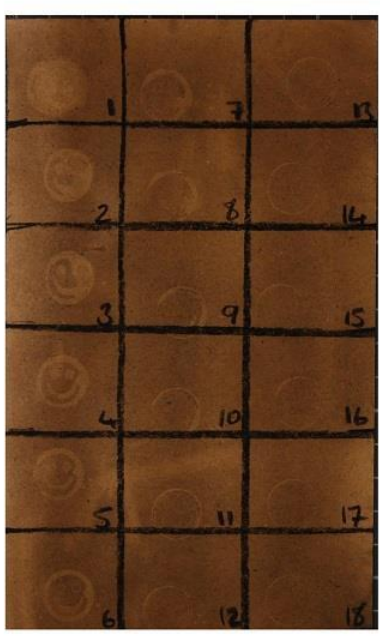

(c)

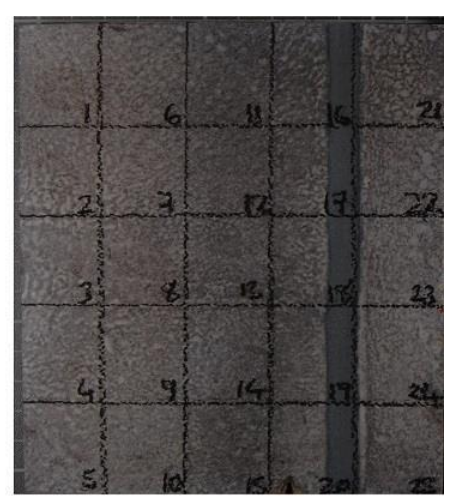

(b)

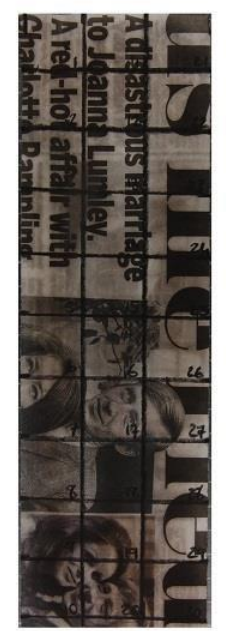

(d)

Figure 6 - Female saliva deposits aged 7 days after enhancement with black magnetic powder and viewed under white light: (a) white ceramic tile; (b) grey laminate flooring; (c) brown envelope and (d) newspaper. 


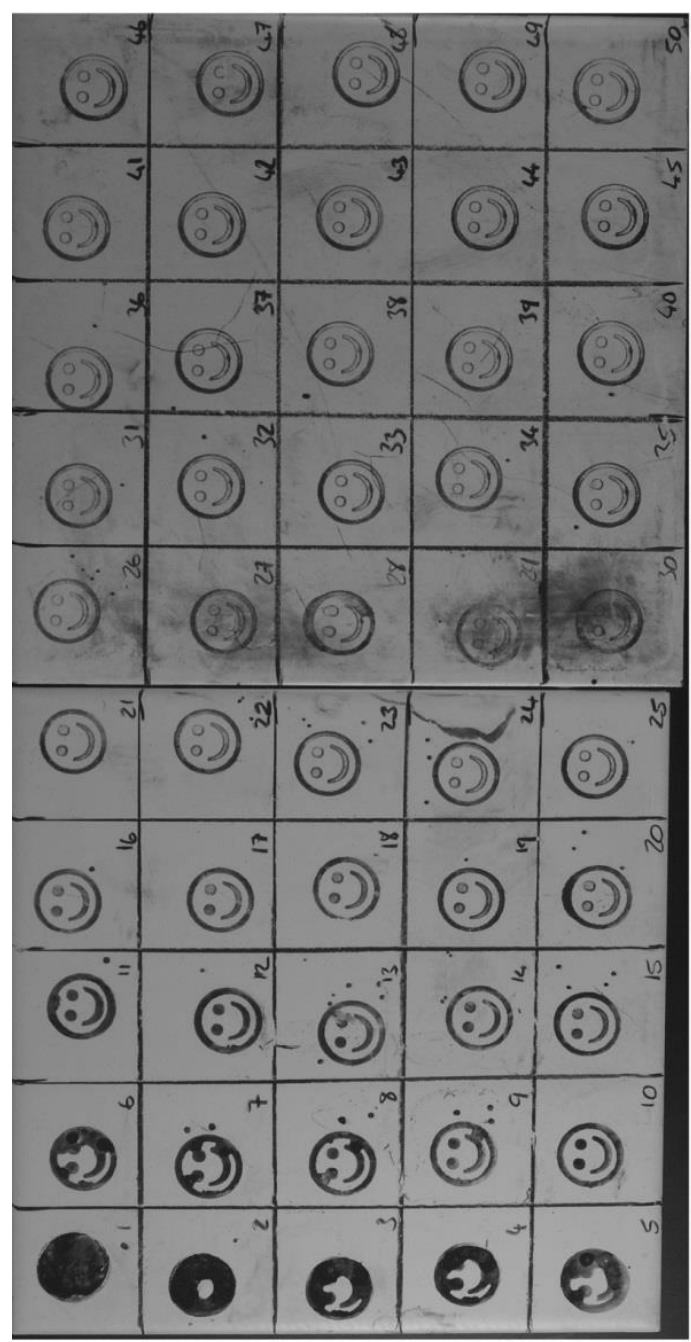

(a)

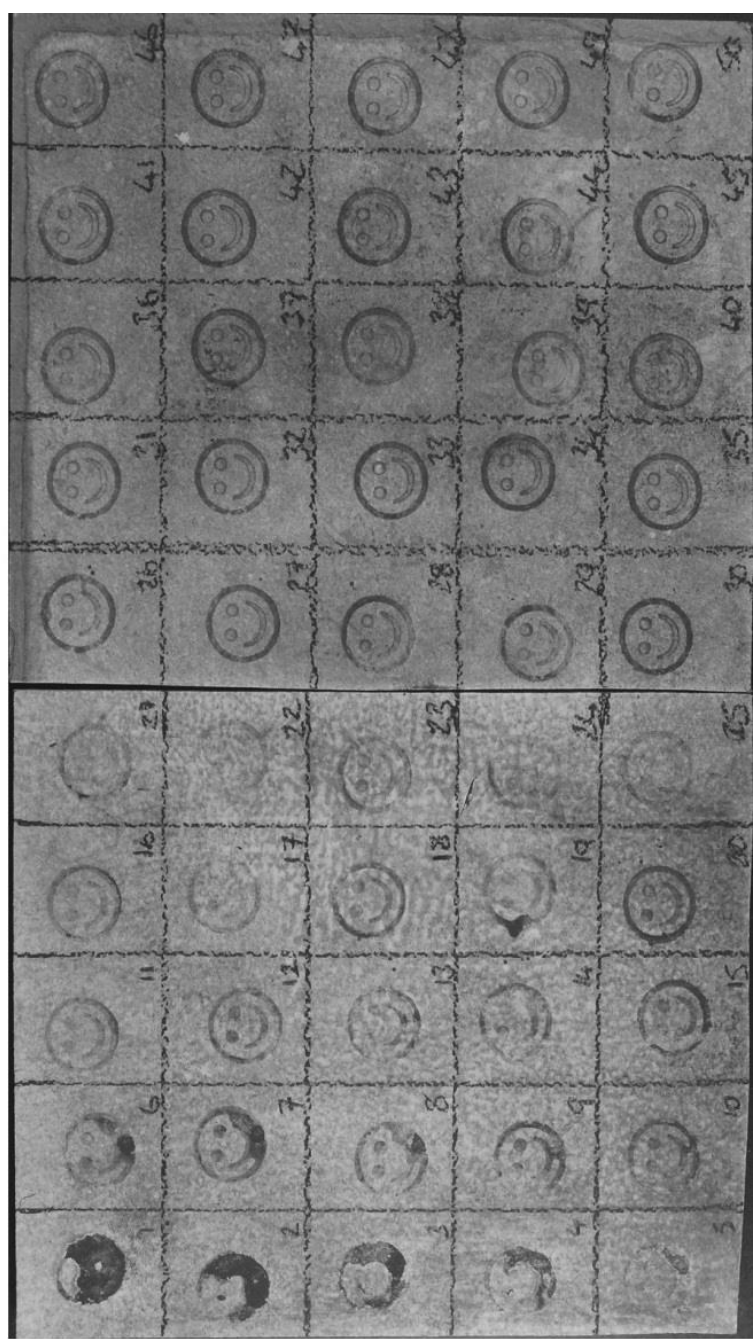

(b)

Figure 7 - Female saliva deposits aged 7 days after enhancement with black iron-oxide powder suspension and viewed under white light: (a) white ceramic tile; (b) grey laminate flooring

After cyanoacrylate fuming, the superglue deposited on any saliva residues present on the substrate, causing a build-up of white polymer. This may be explained by the rehydration of dried constituents within saliva, providing a preferential site for the polymerisation of the cyanoacrylate molecules, resulting in much greater visualisation of the saliva residues. There was no inhibition of the saliva fluorescence post cyanoacrylate fuming and prior to BY40 treatment. The use of BY40 increased the visibility of the polymer under white light, particularly on the white tiles due to the improved contrast (figure 8). BY40 fluorescence allowed the observation of marks further down the depletion series (figures 8 and 9); however, it overpowers the inherent fluorescence of saliva. 


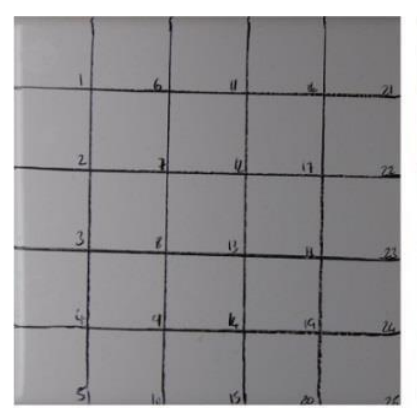

(a)

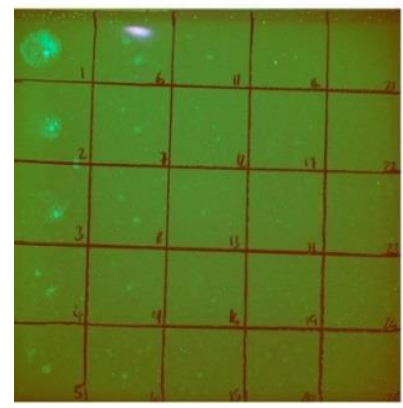

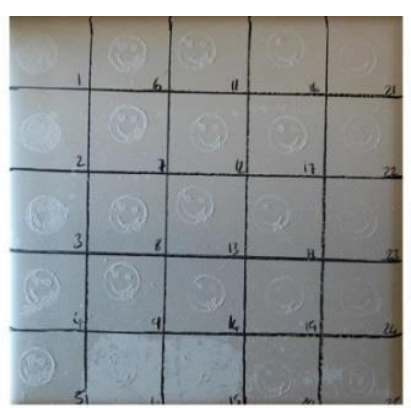

(b)

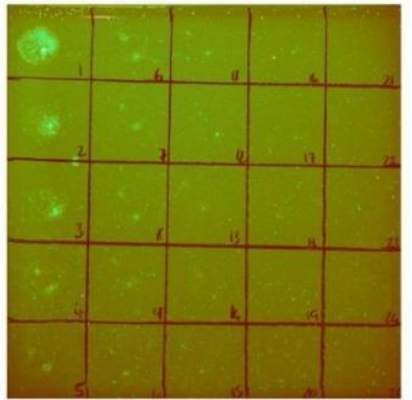

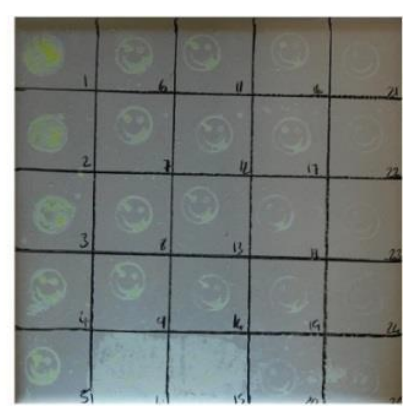

(c)

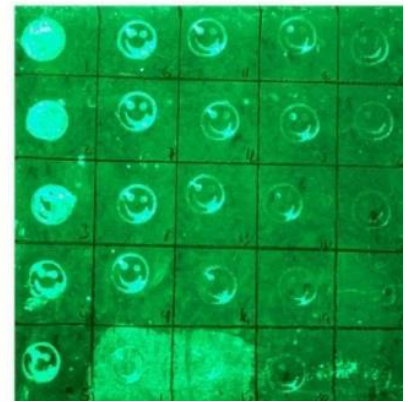

Figure 8 - Male saliva deposits 1-25 in the depletion series on white ceramic tile aged 28 days and viewed under white light [top] (oblique lighting for $b, c$ ) and violet/blue light (yellow filter) [bottom]:

(a) before enhancement; (b) after cyanoacrylate fuming; (c) after cyanoacrylate fuming/B Y40.

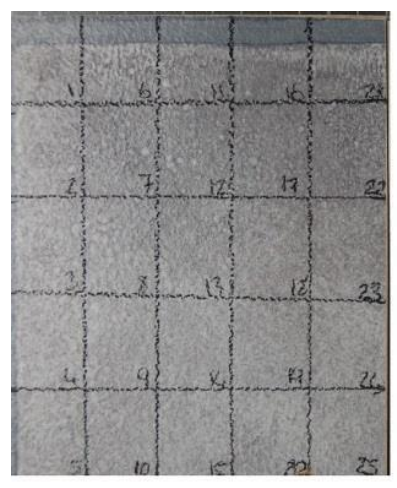

(a)

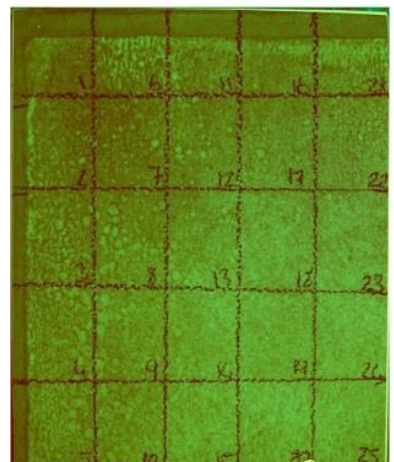

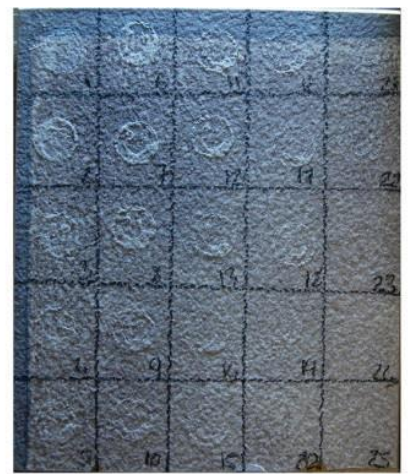

(b)

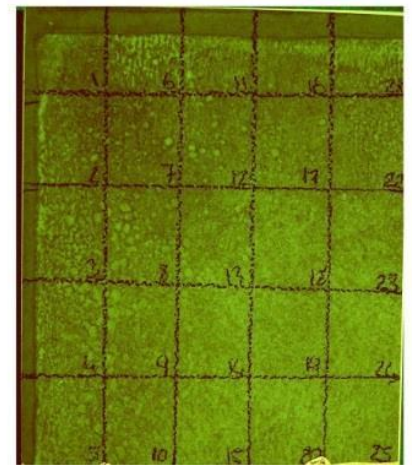

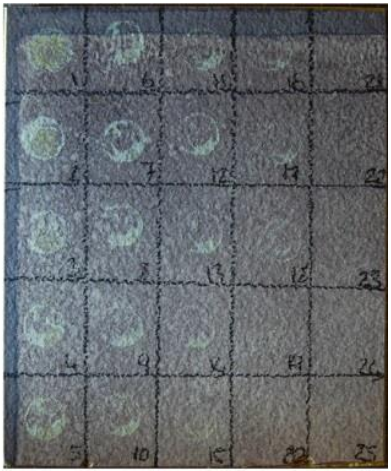

(c)

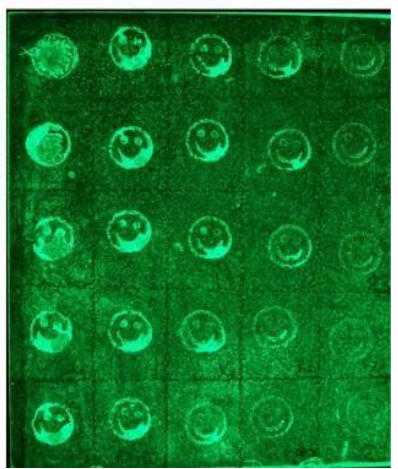

Figure 9 - Male saliva deposits 1-25 in the depletion series on grey laminate flooring aged 28 days and viewed under white light [top] (oblique lighting for $b, c$ ) and violet/blue light (yellow filter) [bottom]:

(a) before enhancement; (b) after cyanoacrylate fuming; (c) after cyanoacrylate fuming/BY40. 
The use of the protein stains AV17 and AY7 enhanced saliva residues with a purple and yellow colouration respectively, resulting in a significantly improved contrast between the residues and the background of the non-porous substrates (figure 10). In general, protein stains are not that effective on porous items; however, AV17 may provide suitable enhancement whereas AY7 is not recommended [1]. For porous substrates, minimal AV17 enhancement was achieved with the first few depletions; however, the intense background staining resulted in poor contrast where the newspaper was the worst offender. AY7 is a fluorescent protein stain and can provide further enhancement when observed under blue light (yellow filter). There was no correlation between the ageing period and the level of enhancement observed using the protein stains.

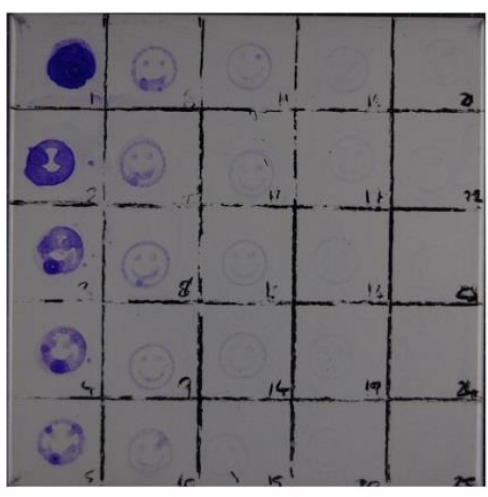

(a)

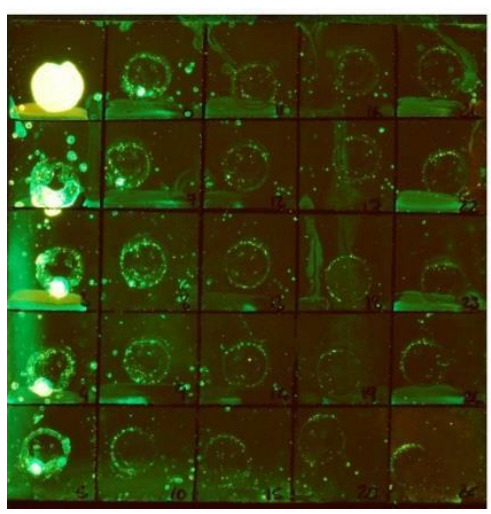

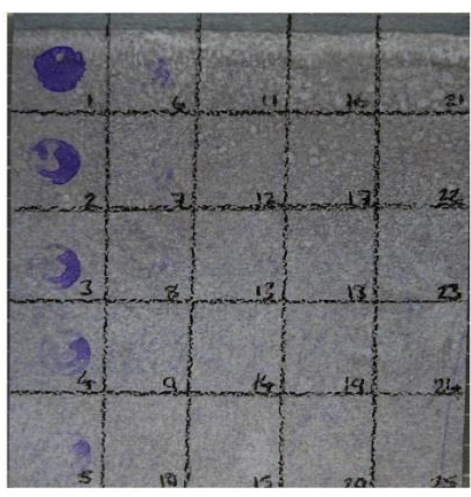

(b)

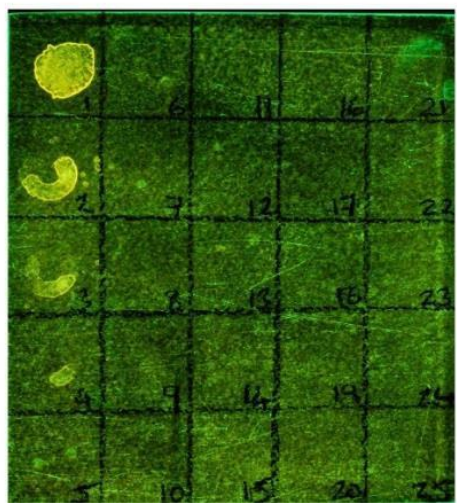

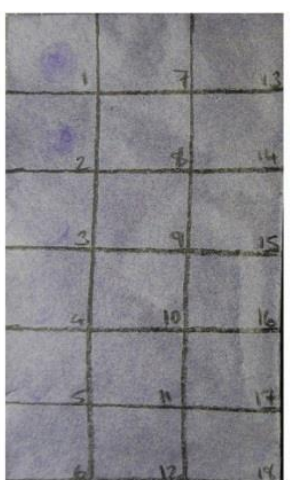

(c)

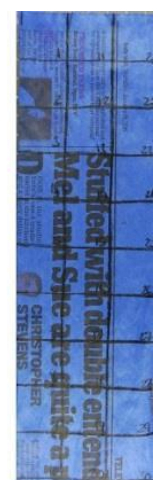

(d)

Figure 10 - Male saliva deposits aged 7 days after enhancement with acid violet 17 (top) observed under white light and acid yellow 7 (bottom) observed under blue light (yellow filter): (a) white ceramic tile; (b) grey laminate flooring; (c) brown envelope and (d) newspaper. 
Whereas the use of protein stains might be suitable for both saliva and blood due to the presence of proteins in both body fluids, the use of luminol is not effective on saliva stains due to the lack of haemoglobin in saliva. Nonetheless, luminol may be employed for the presence of blood and later intelligence may also imply the potential presence of saliva. The use of Bluestar® Forensic Magnum luminol did not provide any visual reaction or enhancement with the saliva residues. As expected, there was no chemiluminescence observed due to the absence of haemoglobin; however, the inherent fluorescence of the saliva residues appeared brighter on non-porous substrates when compared to before treatment. No difference was observed with the porous substrates when comparing before and after enhancement. The use of amino acid reagents on porous substrates provided suitable visualisation on envelopes (figure 11); however, the degree of enhancement decreased with longer ageing periods. The contrast was observed to be significantly better on the envelopes than the newspaper, due to the darker backgrounds of the latter. Marks developed with ninhydrin exhibited a purple colour whereas DFO exhibited little or no visual colouration. The sensitivity of both techniques was good on envelopes but very limited on newspapers. Furthermore, treatment with ninhydrin appeared to inhibit the fluorescence of saliva. Marks enhanced with DFO were observed with a green excitation source (band pass filter 473$548 \mathrm{~nm}$ at $1 \%$ cut-on and cut-off points respectively) and viewed with a band-pass $549 \mathrm{~nm}$ filter (1\% cut-on point). After the reaction with DFO, the inherent fluorescence of saliva was inhibited.

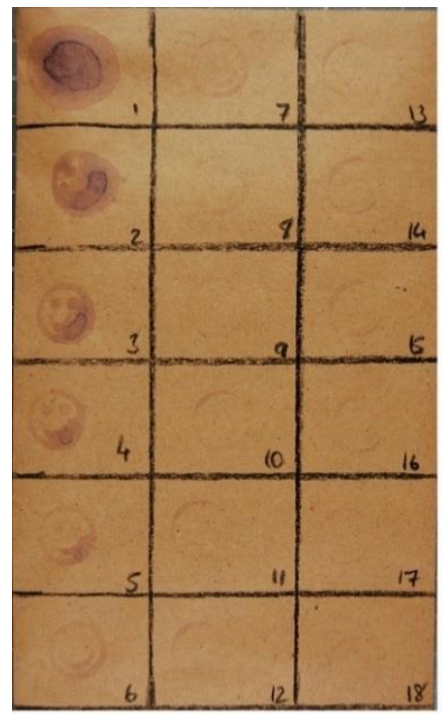

(a)

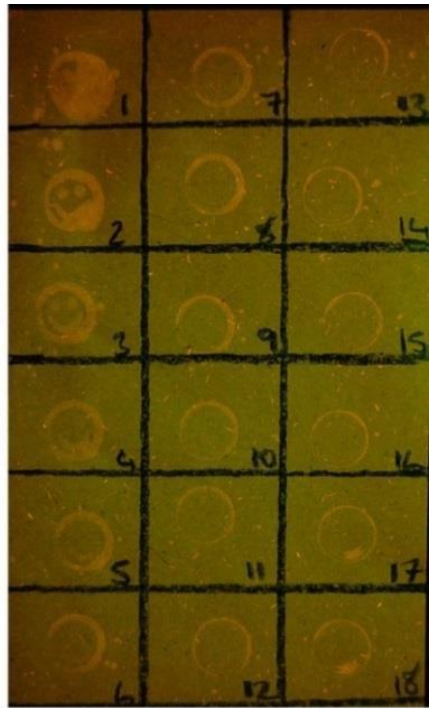

(b)

Figure 11 - Female saliva deposits 1-18 in the depletion series on brown envelope aged 7 days after enhancement with: (a) ninhydrin as observed under white light and (b) DFO as observed with green light (orange filter). 


\section{Phadebas ${ }^{\circledR}$ testing}

Figures 12-14 show the average grading of the Phadebas ${ }^{\circledR}$ reactions for saliva depletions 1 , 18 and 30 (brown envelopes) or 39 (white tiles) in the depletion series across the various enhancement techniques, two ageing periods (1 and 28 days) and two substrates (envelopes and tiles). The results for both the porous and non-porous substrate example were similar whereas the 28 day aged samples provided a weaker reaction when compared to 1 day aged samples. Treatment with iron-oxide powder suspension appeared to have an effect on the Phadebas ${ }^{\circledR}$ tests, with weaker positive results being obtained when compared with the positive controls, potentially due to the removal of water-soluble constituents during the rinsing stage. The use of ninhydrin prior to presumptive testing did not hinder the detection of saliva, although weaker results were observed in comparison to positive controls, and is in accordance with other studies [65]. Preliminary testing with DFO provided similar results to ninhydrin treatment. No positive results were obtained after treatment with AV17 and preliminary testing with AY7, showing protein staining was also detrimental to the Phadebas ${ }^{\circledR}$ presumptive detection of $\alpha$-amylase. It is possible that the water-soluble constituents of the saliva residues were lost, due to the formulations of the fixing and staining solutions being water-based. The use of methanol-based fixatives and protein staining may provide an alternative as reported for the detection of the acid phosphatase for semen [66]. The application of Bluestar ${ }^{\circledR}$ Forensic Magnum luminol and black magnetic powder exhibited minimal effects for the presumptive detection of saliva by Phadebas ${ }^{\circledR}$ testing, even with increasing ageing period and lower down the depletion series. In general, the grading for the Phadebas reaction decreased further down the depletion series due to a lower concentration of $\alpha$-amylase. A negative reaction was recorded for saliva depletion 30 on the porous surface after treatment with ninhydrin; however, the positive control for depletion 30 provided a positive result. This is most likely due to the limit of detection by the Phadebas ${ }^{\circledR}$ reaction rather than the ninhydrin reaction, as evidenced by the positive results for depletions 1 and 18. 


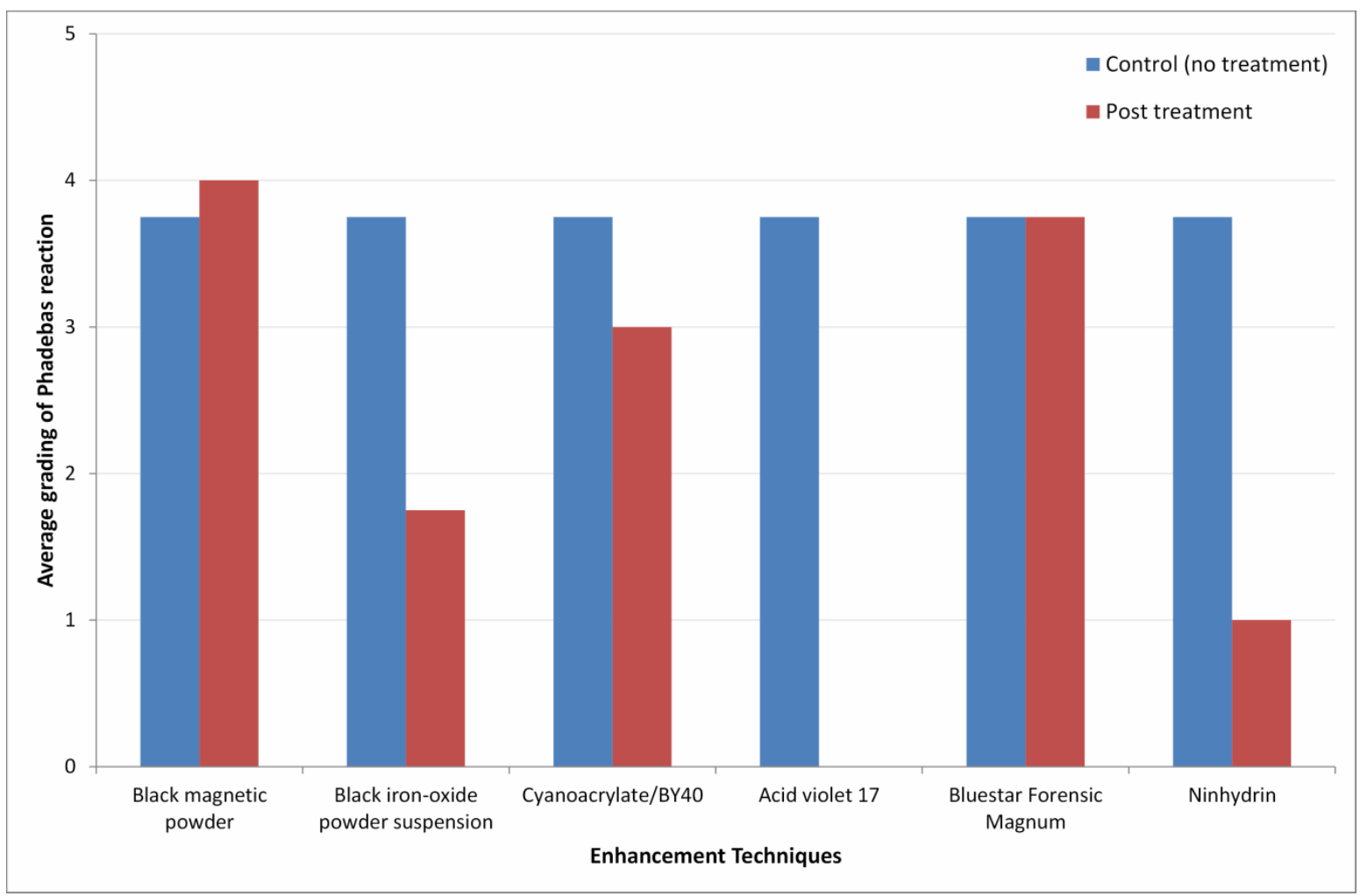

Figure 12 - Average grading of Phadebas reaction for saliva depletion 1 in the depletion series across the various enhancement techniques, two ageing periods ( 1 and 28 days) and two substrates (tiles and envelopes).

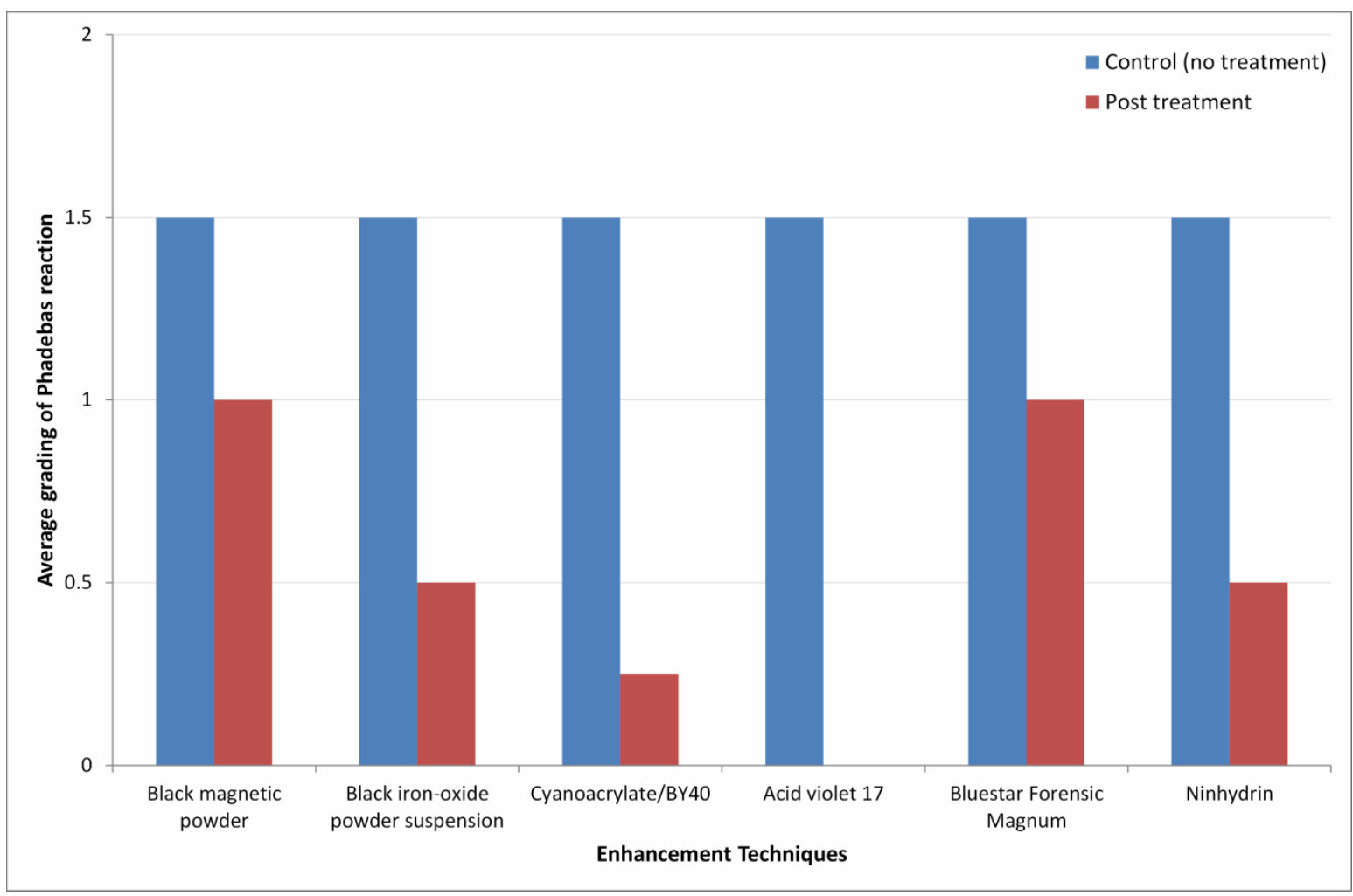

Figure 13 - Average grading of Phadebas reaction for saliva depletion 18 in the depletion series across the various enhancement techniques, two ageing periods ( 1 and 28 days) and two substrates (tiles and envelopes). 


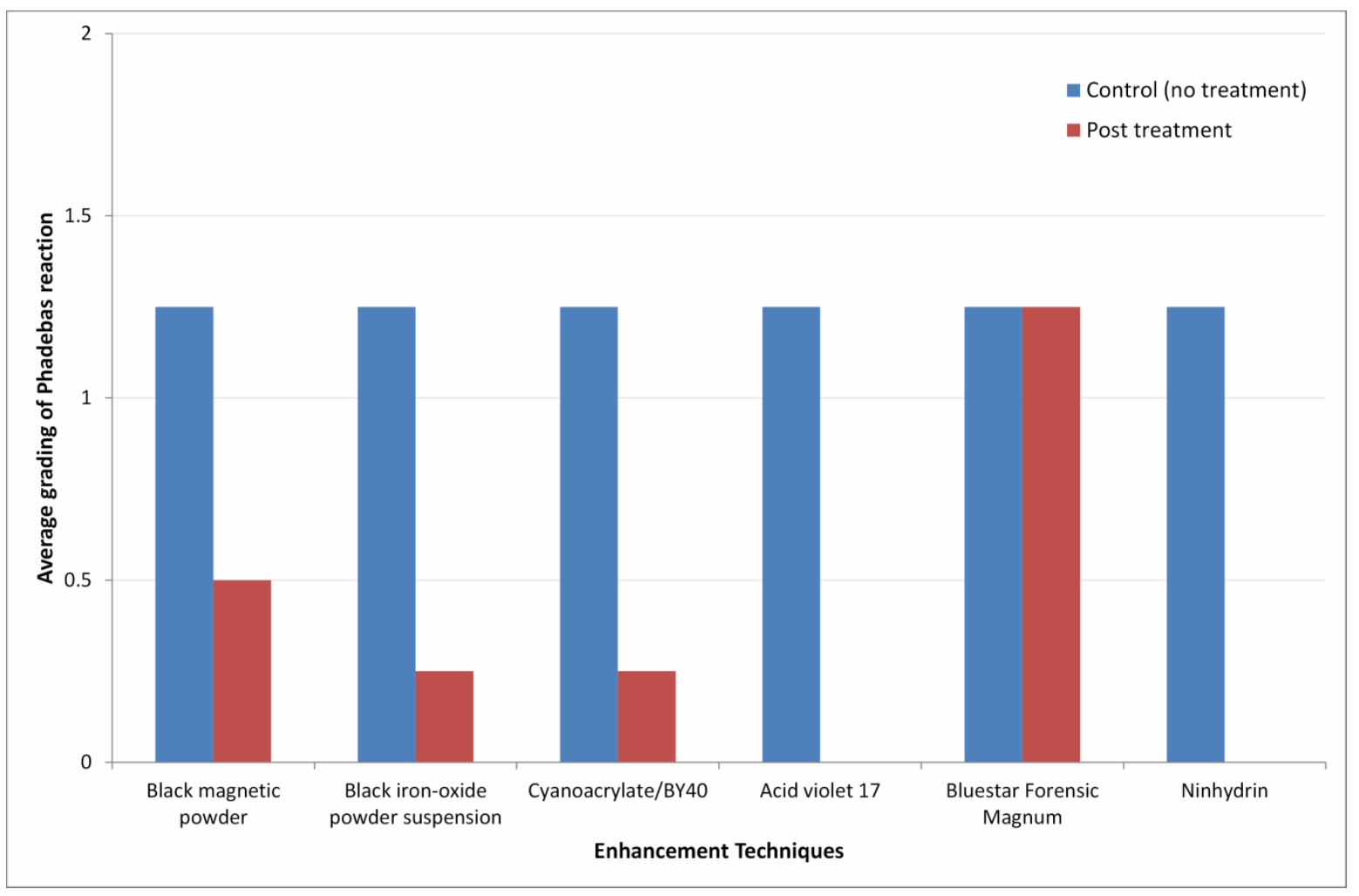

Figure 14 - Average grading of Phadebas reaction for saliva depletion 30/39 in the depletion series across the various enhancement techniques, two ageing periods ( 1 and 28 days) and two substrates (tiles and envelopes).

\section{RSID ${ }^{\text {TM-Saliva Test }}$}

Tables 1 and 2 summarise the results obtained using the RSID-saliva kits on saliva depletions 1,18 and 30/39 in the depletion series across the various enhancement techniques, two ageing periods ( 1 and 28 days) and two substrates (tiles and envelopes). In general, and under the same conditions, more positive reactions were observed on the porous substrate, first depletion and 1 day ageing period. Furthermore, the controls were positive on the weaker deposits whereas a high proportion of the same deposits after treatment with various techniques were negative. Similar to Phadebas ${ }^{\circledR}$ testing, there was no significant effect on reactivity after the use of cyanoacrylate/BY40 and black magnetic powder. The cyanoacrylate polymer may be fixing and protecting the saliva residues on the substrates. Iron-oxide power suspensions and Bluestar ${ }^{\circledR}$ Forensic Mangum provided positive results for the first depletion but were negative further down the depletion series. As reported in previous studies [65], ninhydrin and preliminary work with DFO demonstrated that it is not detrimental to the detection of $\alpha$-amylase by RSID-saliva kits. The protein stain AV17 and preliminary testing with AY7 resulted in a negative result for both substrates, possibly due to presence of water in the fixative agent. 
Table 1 - RSID-saliva testing for 1 day ageing ( $P$ denotes positive; $\mathbf{N}$ denotes negative).

\begin{tabular}{|c|c|c|c|c|c|c|}
\hline & \multicolumn{3}{|c|}{ TILES } & \multicolumn{3}{c|}{ ENVELOPES } \\
\hline & D1 & D18 & D39 & D1 & D18 & D30 \\
\hline PC & P & P & N & P & P & P \\
\hline T1 & P & N & N & P & N & N \\
\hline T2 & N & N & N & P & N & N \\
\hline T3 & P & N & N & P & N & N \\
\hline T4 & N & N & N & N & N & N \\
\hline T5 & P & N & N & P & N & N \\
\hline T6 & P & N & N & P & N & N \\
\hline
\end{tabular}

PC = Positive control, T1 = CA/BY40, T2 = Iron-oxide PS, T3 = Ninhydrin, T4 = AV17, T5 = Bluestar, T6 = BMP

Table 2 - RSID-saliva testing for 28 days ageing ( $P$ denotes positive; $\mathbf{N}$ denotes negative).

\begin{tabular}{|c|c|c|c|c|c|c|}
\hline & \multicolumn{3}{|c|}{ TILES } & \multicolumn{3}{c|}{ ENVELOPES } \\
\hline & D1 & D18 & D39 & D1 & D18 & D30 \\
\hline PC & P & P & N & P & P & P \\
\hline T1 & $\mathrm{P}$ & $\mathrm{N}$ & $\mathrm{N}$ & $\mathrm{P}$ & $\mathrm{N}$ & $\mathrm{N}$ \\
\hline T2 & $\mathrm{P}$ & $\mathrm{N}$ & $\mathrm{N}$ & $\mathrm{P}$ & $\mathrm{N}$ & $\mathrm{N}$ \\
\hline T3 & $\mathrm{N}$ & $\mathrm{N}$ & $\mathrm{N}$ & $\mathrm{P}$ & $\mathrm{N}$ & $\mathrm{N}$ \\
\hline T4 & $\mathrm{N}$ & $\mathrm{N}$ & $\mathrm{N}$ & $\mathrm{N}$ & $\mathrm{N}$ & $\mathrm{N}$ \\
\hline T5 & $\mathrm{N}$ & $\mathrm{N}$ & $\mathrm{N}$ & $\mathrm{P}$ & $\mathrm{N}$ & $\mathrm{N}$ \\
\hline T6 & $\mathrm{P}$ & $\mathrm{N}$ & $\mathrm{N}$ & $\mathrm{P}$ & $\mathrm{P}$ & $\mathrm{N}$ \\
\hline
\end{tabular}

$\mathrm{PC}=$ Positive control, T1 = CA/BY40, T2 = Iron-oxide PS, T3 = Ninhydrin, T4 = AV17, T5 = Bluestar, T6 = BMP

DNA analysis

A summary of the DNA quantification results for depositions 1, 18 and 30/39 sampled after 1 day are provided in Table 3. The amount of DNA recovered was consistent with expectations based on the average amount of human DNA typically observed in saliva samples. Quinque et al. [70] recovered an average of $11.4 \mu \mathrm{g} / \mathrm{ml}$ with a range of $3.9-28.7 \mu \mathrm{g} / \mathrm{ml}$ in a sample of 10 individuals. Based on this data and estimating the amount of saliva deposited by each stamp to be $5 \mu 1$ and an average DNA recovery rate from cotton swabs using the QIAamp DNA Blood mini kit of approximately 40\% [71], DNA quantities recovered were expected to be between $0.14-1.04 \mathrm{ng} / \mu \mathrm{l}$. In this work, DNA quantities recovered ranged from 0.02 $0.23 \mathrm{ng} / \mu \mathrm{l}$, which were lower than that predicted. This estimate does not take into account the absorbent quality of the porous substrate used in this study which is expected to retain a greater proportion of the original deposit than the non-porous tile. Goray et al. [72] have shown that when saliva is deposited onto a porous substrate, cotton as opposed to brown envelope as used in this experiment, only $0.11 \%$ of the DNA deposited in saliva was transferred to a secondary non-porous substrate after the initial deposition. In this same study and under ideal conditions, transfer of wet blood from a non-porous substrate via a non- 
porous secondary substrate with pressure, only $64.1 \%$ of the original deposition was detected. Given this percentage loss, the DNA quantities observed for depletion 1 on day 1 were within expectations. There was no significant difference in the amount of DNA recovered from the porous and non-porous substrates after 1 day ageing ( $\mathrm{p}>0.15$, two-tailed t-test). As the lower detection limit of the quantification kit used is $0.0023 \mathrm{ng} / \mu \mathrm{l}$; the DNA quantification results for deposits 18, 30 and 39 are also within expectations, i.e. undetectable for the majority of samples. It was noted that the positive control sample collected from the envelope produced a DNA yield approximately 4-times greater than all other samples in this set of experiments. As this observation was not replicated for the samples deposited on the tile it cannot be concluded that the difference was due to the use of the enhancement chemicals.

The effect of 28 days ageing before processing was also expected to have an adverse effect on the amount of detectable DNA recovered from the deposition samples whereby a reduction of up to $90 \%$ of useable DNA has been observed after a 3 month delay between sample deposition and collection [47]. The DNA quantification results for depletion samples 1, 18 and 30/39 sampled after 28 days is provided in Table 4. A significant 5-fold reduction in the amount of DNA recovered between day 1 and day 28 samples was observed ( $p<0.05$, porous and $\mathrm{p}<0.01$ non-porous, two-tailed t-test). This reduction was not observed for the positive controls samples whereby the amount of DNA recovered was consistent between day 1 and day 28.

All samples with quantification results $>0.01 \mathrm{ng} / \mu \mathrm{l}$ were additionally processed using the SGM plus PCR amplification kit. This quantity would allow for an input greater than 100pg DNA to each $25 \mu 1$ reaction, a figure traditionally used as the lower limit for detection using the SGM plus amplification kit under standard 28 cycle conditions [73]. The results of SGM plus DNA profiling are provided in Table 5. Of the samples processed for DNA, only depletion 1 samples were suitable for standard DNA profiling analysis. All samples collected after 1 day and $50 \%$ of the samples collected after 28 days contained sufficient DNA for analysis. Of the 1 day ageing samples, full or almost full SGM plus profiles were obtained for all samples except that deposited on the envelope and treated with ninhydrin. Previous studies have also shown successful DNA profiling of fingermarks after ninhydrin treatment $[35,43]$. Another study [74] reported that cyanoacrylate fuming of latent marks on cables resulted in a larger amount of DNA when compared to latent marks that had not been treated indicating that the enhancement technique provides a target area for swabbing that results in a better detection rate. Samples aged 28 days and after treatment with the various enhancement techniques yielded low quantities of DNA resulting in partial profiles only. 
It was possible to generate a complete DNA profile for the day 28 positive control samples. The cause of the disparity between the positive control samples and the test samples for day 28 is unknown. The positive control samples for the DNA aspect of this work were created at a different time to the test samples, using saliva from the same male volunteer but collected on a different day as the original control samples were used for DNA extraction method optimisation. If the saliva collected for the positive control samples contained a greater concentration of DNA than the original samples this may go some way to explaining the inconsistencies observed. The environmental conditions e.g. temperature, humidity and exposure to UV light were not recorded for either test period and may have differed between the two collection periods, which may also have influenced the results.

Table 3 - DNA quantification results for 1 day ageing.

\begin{tabular}{|c|c|c|c|c|c|c|}
\hline & \multicolumn{3}{|c|}{ TILES [DNA] ng/ $\mu \mathrm{l}$} & \multicolumn{3}{c|}{ ENVELOPES [DNA] ng/ $\mu \mathrm{l}$} \\
\hline & $\mathrm{D} 1$ & $\mathrm{D} 18$ & $\mathrm{D} 39$ & $\mathrm{D} 1$ & $\mathrm{D} 18$ & $\mathrm{D} 30$ \\
\hline PC & $0.113^{*}$ & $\mathrm{U}$ & $\mathrm{U}$ & $0.412^{*}$ & $\mathrm{U}$ & $\mathrm{U}$ \\
\hline T1 & $0.139^{*}$ & $\mathrm{U}$ & 0.003 & $0.114^{*}$ & $\mathrm{U}$ & 0.025 \\
\hline T2 & $0.107^{*}$ & $\mathrm{U}$ & $\mathrm{U}$ & $0.022^{*}$ & $\mathrm{U}$ & $\mathrm{U}$ \\
\hline T3 & $0.134^{*}$ & $\mathrm{U}$ & $\mathrm{U}$ & $0.036^{*}$ & $\mathrm{U}$ & 0.002 \\
\hline T4 & $0.165^{*}$ & $\mathrm{U}$ & $\mathrm{U}$ & $0.094^{*}$ & $\mathrm{U}$ & 0.001 \\
\hline T5 & $0.116^{*}$ & $\mathrm{U}$ & $\mathrm{U}$ & $0.230^{*}$ & 0.003 & $\mathrm{U}$ \\
\hline T6 & $0.193^{*}$ & 0.004 & $\mathrm{U}$ & $0.142^{*}$ & 0.004 & $\mathrm{U}$ \\
\hline
\end{tabular}

$\mathrm{PC}=$ Positive control, T1 = CA/BY40, T2 = Iron-oxide PS, T3 = Ninhydrin, T4 = AV17, T5 = Bluestar, T6 = BMP; U = Undetermined DNA quantity; * = Suitable for SGM plus DNA profiling using standard 28 cycle methodology

Table 4 - DNA quantification results for 28 days ageing.

\begin{tabular}{|c|c|c|c|c|c|c|}
\hline & \multicolumn{3}{|c|}{ TILES [DNA] ng/ $\mu$ l } & \multicolumn{3}{c|}{ ENVELOPES [DNA] ng/ $\mu$ l } \\
\hline & D1 & D18 & D39 & D1 & D18 & D30 \\
\hline PC & $0.319^{*}$ & $\mathrm{U}$ & $\mathrm{U}$ & $0.469^{*}$ & $\mathrm{U}$ & 0.003 \\
\hline T1 & 0.009 & $\mathrm{U}$ & $\mathrm{U}$ & $0.011^{*}$ & 0.004 & $\mathrm{U}$ \\
\hline T2 & 0.002 & $\mathrm{U}$ & $\mathrm{U}$ & 0.008 & $\mathrm{U}$ & $\mathrm{U}$ \\
\hline T3 & 0.008 & $\mathrm{U}$ & $\mathrm{U}$ & 0.006 & $\mathrm{U}$ & $\mathrm{U}$ \\
\hline T4 & 0.003 & $\mathrm{U}$ & $\mathrm{U}$ & $0.027^{*}$ & $\mathrm{U}$ & 0.001 \\
\hline T5 & 0.048 & 0.006 & $\mathrm{U}$ & $0.060^{*}$ & $\mathrm{U}$ & $\mathrm{U}$ \\
\hline T6 & $0.110^{*}$ & $\mathrm{U}$ & $\mathrm{U}$ & $0.021^{*}$ & $\mathrm{U}$ & $\mathrm{U}$ \\
\hline
\end{tabular}

$\mathrm{PC}=$ Positive control, T1 = CA/BY40, T2 = Iron-oxide PS, T3 = Ninhydrin, T4 = AV17, T5 = Bluestar, T6 = BMP; U = Undetermined DNA quantity; * = Suitable for SGM plus DNA profiling using standard 28 cycle methodology 
Table 5 - Summary of SGM plus DNA profiling results.

\begin{tabular}{|c|c|c|c|c|}
\hline & \multicolumn{2}{|c|}{$\begin{array}{c}\text { TILES - Depletion 1 } \\
\text { (\% alleles observed) }\end{array}$} & \multicolumn{2}{c|}{$\begin{array}{c}\text { ENVELOPES - Depletion 1 } \\
\text { (\% alleles observed) }\end{array}$} \\
\hline & Day 1 & Day 28 & Day 1 & Day 28 \\
\hline PC & 100 & 100 & 100 & 100 \\
\hline T1 & 100 & NA & 100 & 0 \\
\hline T2 & 100 & NA & 100 & NA \\
\hline T3 & 100 & NA & 40 & NA \\
\hline T4 & 100 & NA & 100 & 45 \\
\hline T5 & 95 & 50 & 100 & 55 \\
\hline T6 & 100 & 60 & 100 & 45 \\
\hline
\end{tabular}

Results are presented as a percentage of the maximum number of alleles detected (20) using the SGM plus amplification kit. Amelogenin $\mathrm{X}$ and $\mathrm{Y}$ peaks were observed in all amplified samples as expected but were not used for calculation of percentage profile results. $\mathrm{PC}=$ Positive control, $\mathrm{T} 1=\mathrm{CA} / \mathrm{BY} 40$, T2 = Iron-oxide PS, T3 = Ninhydrin, T4 = AV17, T5 = Bluestar, T6 = BMP, NA = No amplification attempted due to low quantification result. 


\section{Summary}

Table 6 summarises the results observed in this study as to the effects of the various enhancement techniques on the subsequent detection of saliva depletion 1 by means of Phadebas $^{\circledR}$ testing, RSID $^{\mathrm{TM}}$-saliva kits and DNA analysis. The amount of saliva in depletion 1 is higher than what would be found in crime scene stains and further work is required to thoroughly assess how the tests operate further down the depletion series. Additionally, the limit of detection of such tests should also be assessed.

Table 6 - A summary of the effects of the enhancement techniques on the subsequent detection of saliva on depletion 1 of the series.

\begin{tabular}{|l|c|c|c|c|}
\hline & $\begin{array}{c}\text { Improved } \\
\text { Visual } \\
\text { Examination }\end{array}$ & $\begin{array}{c}\text { Phadebas }^{\circledR} \\
\text { Testing }\end{array}$ & $\begin{array}{c}\text { RSID }^{\text {TM_ }} \\
\text { Saliva Testing }\end{array}$ & DNA Analysis \\
\hline Cyanoacrylate /BY40 & $\checkmark$ & $\checkmark$ & $\checkmark$ & $\checkmark$ \\
\hline Iron-oxide PS & $\checkmark$ & $\checkmark$ & $\checkmark$ & $\checkmark$ \\
\hline Ninhydrin & $\checkmark$ & $\checkmark$ & X & $\checkmark$ \\
\hline Acid Violet 17 & $\checkmark$ & X & $\checkmark$ & $\checkmark$ \\
\hline $\begin{array}{l}\text { Bluestar } \\
\text { Magnum }\end{array}$ & Forensic & $\checkmark$ & $\checkmark$ & $\checkmark$ \\
\hline Black Magnetic Powder & $\checkmark$ & $\checkmark$ & $\checkmark$ & $\checkmark$ \\
\hline
\end{tabular}

DNA results for Day 1, deposition 1 only. Full SGM plus DNA profile produced for all samples apart from saliva enhanced with ninhydrin on the porous substrate, where 8/20 STR alleles were observed following standard methodology. Chemical treatment, Phadebas and RSID testing on all substrates; DNA analysis on white tile and brown envelope. 


\section{Conclusion}

This study demonstrated that the enhancement techniques, with the exception of Bluestar ${ }^{\circledR}$ Forensic Magnum luminol, improved the visualisation of saliva more prominently on nonporous substrates. The visualisation of saliva stains by latent enhancement techniques provides a target area for swabbing for subsequent presumptive, confirmative and DNA tests. If the stains are not visualised in the first instance, then speculative swabbing must be done which may be detrimental to the fine detail of latent marks.

It has been demonstrated that the enhancement techniques employed in this study, with the exception of AV17 and AY7, did not adversely affect the subsequent detection of saliva. The use of protein stains inhibited the presumptive Phadebas ${ }^{\circledR}$ test for saliva and the confirmatory RSID $^{\mathrm{TM}}$ test but not the recovery of DNA material. The DNA analysis was largely unaffected by the enhancement techniques although some inhibition was observed with ninhydrin. The recovery of DNA from enhanced latent marks may provide different results due to a saliva stain containing a much larger amount of cellular material. Some anomalies were observed in the DNA recovery results which may be explained by a number of points such as the fact that the saliva was obtained from the same donor on different days.

A further limitation of the study was that the methodology was not flexible in terms of which saliva stains were tested for further presumptive and confirmative tests i.e. depletions 1,18 and 30 for porous surfaces and depletions 1, 18 and 39 for non-porous surfaces. Perhaps a better approach would be to take three depletions as follows: a saliva stain that is visible prior to any treatment with enhancement techniques, another saliva stain at the limit of visualisation detection by the enhancement technique and another saliva stain in between this range. The three depletions selected would vary and be dependent on the nature of the substrate, enhancement technique and ageing period. An integrated approach for a number of body fluids has been performed and future work will investigate an integrated approach for the detection of blood (most prevalent body fluid) and latent marks. 


\section{References}

[1] Home Office, Fingermark Visualisation Manual, 2014.

[2] K. Virkler, I.K. Lednev, Analysis of body fluids for forensic purposes: From laboratory testing to non-destructive rapid confirmatory identification at a crime scene, Forensic Sci. Int. 188 (2009) 1-17.

[3] A. Gunn, Essential Forensic Biology, Wiley-Blackwell, 2009.

[4] J.W. Bond, C. Hammond, The value of DNA material recovered from crime scenes, J. Forensic Sci. 53 (2008) 797-801.

[5] J. Hedman, E. Dalin, B. Rasmusson, R. Ansell, Evaluation of amylase testing as a tool for saliva screening of crime scene trace swabs., Forensic Sci. Int. Genet. 5 (2011) 194-8.

[6] B.C.M. Pang, B.K.K. Cheung, Applicability of two commercially available kits for forensic identification of saliva stains., J. Forensic Sci. 53 (2008) 1117-22.

[7] J. Auvdel, Michael, Amylase Levels in Semen and Saliva Stains, J. Forensic Sci. 31 (1986) $426-431$.

[8] A.E. Kipps, P.H. Whitehead, T. British, L. Document, S. Service, B. Spa, et al., The significance of amylase in forensic investigations of body fluids, Forensic Sci. 6 (1975) 137144.

[9] P.H. Whitehead, a E. Kipps, A test paper for detecting saliva stains., J. Forensic Sci. Soc. 15 (1975) 39-42. http://www.ncbi.nlm.nih.gov/pubmed/1159385.

[10] M. Stoilovic, Detection of semen and blood stains using polilight as a light source, Forensic Sci. Int. 51 (1991) 289-296. http://www.sciencedirect.com/science/article/B6T6W-4C35YNJNV/2/7bb4f61080ecd8052fd270bac5171caf.

[11] N. Vandenberg, R. a H. van Oorschot, The use of Polilight in the detection of seminal fluid, saliva, and bloodstains and comparison with conventional chemical-based screening tests., J. Forensic Sci. 51 (2006) 361-70.

[12] A. Fiedler, J. Rehdorf, F. Hilbers, L. Johrdan, C. Stribl, M. Benecke, Detection of Semen (Human and Boar) and Saliva on Fabrics by a Very High Powered UV- / VIS-Light Source, Open Forensic Sci. J. 1 (2008) 12-15.

[13] K. Virkler, I.K. Lednev, Raman spectroscopy offers great potential for the nondestructive confirmatory identification of body fluids., Forensic Sci. Int. 181 (2008) e1-5.

[14] K. Virkler, I.K. Lednev, Forensic body fluid identification: the Raman spectroscopic signature of saliva., Analyst. 135 (2010) 512-517.

[15] V. Sikirzhytski, K. Virkler, I.K. Lednev, Discriminant analysis of Raman spectra for body fluid identification for forensic purposes, Sensors. 10 (2010) 2869-2884.

[16] K.D.S. Nanda, K. Ranganathan, K. Umadevi, E. Joshua, A rapid and noninvasive method to detect dried saliva stains from human skin using fluorescent spectroscopy., J. Oral Maxillofac. Pathol. 15 (2011) 22-25. 
[17] N. Frascione, R. Thorogate, B. Daniel, S. Jickells, Detection and identification of body fluid stains using antibody-nanoparticle conjugates, Analyst. 137 (2012) 508.

[18] D.F. Nelson, P.L. Kirk, The identification of saliva, J. Forensic Med. 10 (1963) 14-21.

[19] R.E. Gaensslen, Sourcebook in Forensic Serology, Immunology and Biochemistry, U.S. Department of Justice, Washington DC, 1983.

[20] G.M. Willott, An improved test for the detection of salivary amylase in stains., J. Forensic Sci. Soc. 14 (1974) 341-4. http://www.ncbi.nlm.nih.gov/pubmed/4443789.

[21] S.J. Gutowski, P.L. Henthorn, The preliminary evaluation of a commercial test kit in the identification of saliva., J. Forensic Sci. Soc. 23 (1983) 135-7.

http://www.ncbi.nlm.nih.gov/pubmed/6192198.

[22] J. Hedman, K. Gustavsson, R. Ansell, Using the new Phadebas® Forensic Press test to find crime scene saliva stains suitable for DNA analysis, Forensic Sci. Int. Genet. Suppl. Ser. 1 (2008) 430-432.

[23] R. Li, Forensic Biology, Second Edi, CRC Press, London, 2015.

[24] J.R. Myers, W.K. Adkins, Comparison of modern techniques for saliva screening., J. Forensic Sci. 53 (2008) 862-7.

[25] T.L. Reena Roy, Ultraviolet-Visible Spectrophotometry (UV-VIS) and SALIgAE® Qualitative and Semi-quantitative Tools for the Analysis of Salivary Amylase, J. Forensic Res. 05 (2014).

[26] A. Sinelnikov, A. Kalinina, J. Old, P. Boonlayangoor, K. Reich, Evaluation of Rapid Stain IDentification $\left(\mathrm{RSID}^{\mathrm{TM}}\right)$ Reader System for Analysis and Documentation of RSID ${ }^{\mathrm{TM}}$ Tests, Appl. Sci. 3 (2013) 624-635.

[27] J. Old, B. a. Schweers, P.W. Boonlayangoor, B. Fischer, K.W.P. Miller, K. Reich, Developmental Validation of RSID ${ }^{\mathrm{TM}}$-Semen: A Lateral Flow Immunochromatographic Strip Test for the Forensic Detection of Human Semen, J. Forensic Sci. 57 (2012) 489-499.

[28] D.G. Casey, J. Price, The sensitivity and specificity of the RSID-saliva kit for the detection of human salivary amylase in the Forensic Science Laboratory, Dublin, Ireland., Forensic Sci. Int. 194 (2010) 67-71.

[29] H.-Y. Park, B.-N. Son, Y.-I. Seo, S.-K. Lim, Comparison of Four Saliva Detection Methods to Identify Expectorated Blood Spatter, J. Forensic Sci. 60 (2015) 1571-1576.

[30] E. Valls Trepat, A. Castelló, More about RSID-saliva: the effect of sample age and the environment on the test's efficacy, Aust. J. Forensic Sci. (2015) 1-6.

[31] A. Castelló, F. Francès, F. Verdú, The effectiveness of the RSID confirmatory test kit for human alpha amylase: the effects of environmental factors and substrate materials, Aust. J. Forensic Sci. (2016).

[32] U. Ricci, I. Carboni, F. Torricelli, False-positive results with amylase testing of citrus fruits, J. Forensic Sci. 59 (2014) 1410-2. 
[33] A. Feia, N. Novroski, The Evaluation of Possible False Positives with Detergents when Performing Amylase Serological Testing on Clothing, J. Forensic Sci. 58 (2013) 183-185.

[34] H.C. Lee, R.E. Gaensslen, E.M. Pagliaro, M.B. Guman, K.M. Berka, T.P. Keith, et al., The effect of presumptive test, latent fingerprints and some other reagents \& materials on subsequent serological identification, genetic marker \& DNA testing in bloodstains., J. Forensic Identif. 39 (1989) 339-358.

[35] C. Stein, S.H. Kyeck, C. Henssge, DNA typing of fingerprint reagent treated biological stains., J. Forensic Sci. 41 (1996) 1012-1017.

[36] J. Andersen, S. Bramble, The effects of fingermark enhancement light sources on subsequent PCR-STR DNA analysis of fresh bloodstains., J. Forensic Sci. 42 (1997) 303-306.

[37] D.E.O. Van Hoofstat, D.L.D. Deforce, I.P. Hubert De Pauw, E.G. Van Den Eeckhout, DNA typing of fingerprints using capillary electrophoresis: Effect of dactyloscopic powders, Electrophoresis. 20 (1999) 2870-2876.

[38] B. Budowle, J.L. Leggitt, D.A. Defanbaugh, K.M. Keys, S.F. Malkiewicz, The Presumptive Reagent Fluorescein for the Detection of Dilute Bloodstains and subsequent STR Typing of Recovered DNA, J. Forensic Sci. 45 (2000) 1090-1092.

[39] a Zamir, E. Springer, B. Glattstein, Fingerprints and DNA: STR typing of DNA extracted from adhesive tape after processing for fingerprints., J. Forensic Sci. 45 (2000) 687-688.

[40] N. von Wurmb, D. Meissner, R. Wegener, Influence of cyanoacrylate on the efficiency of forensic PCRs, Forensic Sci. Int. 124 (2001) 11-16.

[41] M. Azoury, A. Zamir, C. Oz, S. Wiesner, The Effect of 1,2-Indanedione, a latent fingerprint reagent, on subsequent DNA profiling, J. Forensic Sci. 47 (2002) 586-588.

[42] M.K. Balogh, J. Burger, K. Bender, P.M. Schneider, K.W. Alt, STR genotyping and mtDNA sequencing of latent fingerprint on paper, Forensic Sci. Int. 137 (2003) 188-195.

[43] M.M. Schulz, H.-D. Wehner, W. Reichert, M. Graw, Ninhydrin-dyed latent fingerprints as a DNA source in a murder case., J. Clin. Forensic Med. 11 (2004) 202-4.

[44] C. Roux, E. Du Pasquier, J. Sutton, C. Lennard, The Effect of Common Fingerprint Detection Techniques on the DNA Typing of Fingerprints Deposited on Different Surfaces, J. Forensic Identif. 54 (2004) 22-44.

[45] J. Jakovich, STR Analysis Following Latent Blood Detection by Luminol, Fluorescein, and Bluestar, J. Forensic Identif. 57 (2007) 193.

[46] P.-H. Yu, M.M. Wallace, Effect of 1,2-indanedione on PCR-STR typing of fingerprints deposited on thermal and carbonless paper., Forensic Sci. Int. 168 (2007) 112-8.

[47] T.W. Bille, C. Cromartie, M. Farr, Effects of cyanoacrylate fuming, time after recovery, and location of biological material on the recovery and analysis of DNA from post-blast pipe bomb fragments, J. Forensic Sci. 54 (2009) 1059-1067. 
[48] B. Bhoelai, B.J. de Jong, M. de Puit, T. Sijen, Effect of common fingerprint detection techniques on subsequent STR profiling, Forensic Sci. Int. Genet. Suppl. Ser. 3 (2011) e429e430.

[49] S. Gino, M. Omedei, Effects of the most common methods for the enhancement of latent fingerprints on DNA extraction from forensic samples, Forensic Sci. Int. Genet. Suppl. Ser. 3 (2011) e273-e274.

[50] C. Thamnurak, W. Bunakkharasawat, S. Riengrojpitak, N. Panvisavas, DNA typing from fluorescent powder dusted latent fingerprints, Forensic Sci. Int. Genet. Suppl. Ser. 3 (2011) e524-e525.

[51] S. Norlin, M. Nilsson, P. Heden, M. Allen, Evaluation of the Impact of Different Visualization Techniques on DNA in Fingerprints, J. Forensic Identif. 63 (2013) 189-204.

[52] P. Tozzo, A. Giuliodori, D. Rodriguez, L. Caenazzo, Effect of dactyloscopic powders on DNA profiling from enhanced fingerprints: results from an experimental study., Am. J. Forensic Med. Pathol. 35 (2014) 68-72.

[53] L.-C. Tsai, C.-C. Lee, C.-C. Chen, J.C.-I. Lee, S.-M. Wang, N.-E. Huang, et al., The Influence of Selected Fingerprint Enhancement Techniques on Forensic DNA Typing of Epithelial Cells Deposited on Porous Surfaces, J. Forensic Sci. 61 (2016) S221-S225.

[54] P.-A. Bolivar, M. Tracey, B. McCord, Assessing the Risk of Secondary Transfer Via Fingerprint Brush Contamination Using Enhanced Sensitivity DNA Analysis Methods, J. Forensic Sci. 61 (2016) 204-211.

[55] S. a. Steadman, S.R. Hoofer, S.C. Geering, S. King, M. a. Bennett, Recovery of DNA from Latent Fingerprint Tape Lifts Archived Against Matte Acetate, J. Forensic Sci. 60 (2015) 777 782.

[56] P. Kumar, R. Gupta, R. Singh, O.P. Jasuja, Effects of latent fingerprint development reagents on subsequent forensic DNA typing: A review, J. Forensic Leg. Med. 32 (2015) 64-69.

[57] D. Wilkinson, S. Larocque, P. Lecavalier, S. Cairns, The Recovery of Footwear Evidence from Crime Scenes Contaminated with Chemical Warfare Agents, Identif. Canada. 28 (2005) 4-19.

[58] R. Hoile, S.J. Walsh, C. Roux, Bioterrorism: Processing Contaminated Evidence, the Effects of Formaldeyhde Gas on the Recovery of Fingermarks, J. Forensic Sci. 52 (2007) 1097-1102.

[59] D. Wilkinson, S. Larocque, C. Astle, J. Vogrinetz, The Effects of Aerosolized Bacteria on Fingerprint Impression Evidence, J. Forensic Identif. 59 (2009) 65-79.

[60] M. Scott, Does CA fuming interfere with powder suspension processing?, J. Forensic Identif. 59 (2009) 144-151.

[61] J. Vaughan, The Effects of Bluestar on the Kastle-Meyer Presumptive Test for Blood, J. Forensic Identif. 61 (2011) 38-49.

[62] N. Passi, R.K. Garg, M. Yadav, R.S. Singh, M.A. Kharoshah, Effect of luminol and bleaching agent on the serological and DNA analysis from bloodstain, Egypt. J. Forensic Sci. 2 (2012) $54-61$. 
[63] S. King, S. Benson, T. Kelly, C. Lennard, Determining the effects of routine fingermark detection techniques on the subsequent recovery and analysis of explosive residues on various substrates, Forensic Sci. Int. 233 (2013) 257-264.

[64] M.C. Zuidberg, T. van Woerkom, K.G. de Bruin, R.D. Stoel, M. de Puit, Effects of CBRN decontaminants in common use by first responders on the recovery of latent fingerprints-assessment of the loss of ridge detail on glass., J. Forensic Sci. 59 (2014) 61-9.

[65] S.E. Bitner, J.R. Clark, M.M. Priestley, B. Ziencik, The Effects of Ninhydrin Processing on Common $\alpha$-Amylase Tests, J. Forensic Identif. 63 (2013) 503-513.

[66] R. Simmons, P. Deacon, D.J. Phillips, K. Farrugia, The effect of mark enhancement techniques on the subsequent detection of semen/spermatozoa, Forensic Sci. Int. 244 (2014) 231-246.

[67] M. Castagnola, D. Congiu, G. Denotti, A. Di Nunzio, M.B. Fadda, S. Melis, et al., Determination of the human salivary peptides histatins $1,3,5$ and statherin by highperformance liquid chromatography and by diode-array detection, J. Chromatogr. B Biomed. Sci. Appl. 751 (2001) 153-160.

[68] D. Sweet, D. Ph, M. Lorente, J.A. Lorente, A. Valenzuela, E. Villanueva, et al., An Improved Method to Recover Saliva from Human Skin : The Double Swab Technique, J. Forensic Sci. 42 (1997) 320-322.

[69] Independent Forensics, Rapid Stain Identification of Human Saliva (RSID ${ }^{\mathrm{TM}}$-Saliva), (2011). http://www.ifi-test.com/wp-content/uploads/2014/02/Saliva-UniversalBuffer.pdf (accessed September 17, 2015).

[70] D. Quinque, R. Kittler, M. Kayser, M. Stoneking, I. Nasidze, Evaluation of saliva as a source of human DNA for population and association studies., Anal. Biochem. 353 (2006) 272-7.

[71] R.J. Brownlow, K.E. Dagnall, C.E. Ames, A Comparison of DNA Collection and Retrieval from Two Swab Types (Cotton and Nylon Flocked Swab) when Processed Using Three QIAGEN Extraction Methods, J. Forensic Sci. 57 (2012) 713-717.

[72] M. Goray, E. Eken, R.J. Mitchell, R.A.H. van Oorschot, Secondary DNA transfer of biological substances under varying test conditions., Forensic Sci. Int. Genet. 4 (2010) 62-7.

[73] P. Gill, J. Whitaker, C. Flaxman, N. Brown, J. Buckleton, An investigation of the rigor of interpretation rules for STRs derived from less than $100 \mathrm{pg}$ of DNA, Forensic Sci. Int. 112 (2000) 17-40.

[74] S. Lim, Z. Subhani, B. Daniel, N. Frascione, Touch DNA - the prospect of DNA profiles from cables, Sci. Justice. 56 (2016) 210-215. 